\title{
Towards Sustainability Pathway with Bio-Derived Platinum and Palladium Catalyst for Furfural Hydrogenation-A Novel Greener Approach in Catalysis
}

\author{
Babatunde J. Akinbile (D, Leah C. Matsinha, Banothile C. E. Makhubela and Abayneh A. Ambushe *(D)
}

check for

updates

Citation: Akinbile, B.J.; Matsinha, L.C.; Makhubela, B.C.E.; Ambushe, A.A. Towards Sustainability Pathway with Bio-Derived Platinum and Palladium Catalyst for Furfural Hydrogenation-A Novel Greener Approach in Catalysis. Minerals 2021, 11, 895. https://doi.org/10.3390/ $\min 11080895$

Academic Editor: Yan Li

Received: 15 July 2021

Accepted: 9 August 2021

Published: 19 August 2021

Publisher's Note: MDPI stays neutral with regard to jurisdictional claims in published maps and institutional affiliations.

Copyright: (c) 2021 by the authors. Licensee MDPI, Basel, Switzerland. This article is an open access article distributed under the terms and conditions of the Creative Commons Attribution (CC BY) license (https:// creativecommons.org/licenses/by/ $4.0 /)$.
Research Centre for Synthesis and Catalysis, Department of Chemical Sciences, University of Johannesburg, Auckland Park, Johannesburg 2006, South Africa; tundeakinbile1@yahoo.com (B.J.A.); lmatsinha@uj.ac.za (L.C.M.); bmakhubela@uj.ac.za (B.C.E.M.)

* Correspondence: aambushe@uj.ac.za; Tel.: +27-11-559-2329; Fax: +27-11-559-2819

Abstract: The use of living plants to recover precious metals with potential catalytic activity is still at the infant stage. In this study, selective hydrogenation of furfural to furfuryl alcohol using novel bio-ore catalysts recovered from the end stage of phytomining process is demonstrated. The phytomining process was carried out in the green house by artificially contaminating cassava (Manihot esculenta) plant with $500 \mathrm{mg} / \mathrm{L}$ palladium $(\mathrm{Pd})$ and platinum $(\mathrm{Pt})$ solutions for a period of eight weeks. After harvesting, concentrations of metals as high as $78 \pm 0.047$ and $1276 \pm 0.036 \mu \mathrm{g} / \mathrm{g}$ of $\mathrm{Pd}$ and $\mathrm{Pt}$, respectively, were detected in the calcinated root of cassava. The produced bio-ore catalysts; @PdCassCat and @PtCassCat were fully characterized with the following techniques: transmission electron microscopy (TEM), scanning electron microscopy with energy dispersive

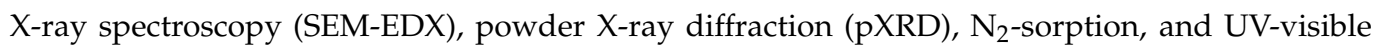
spectroscopy techniques and directly applied as catalysts for hydrogenation of furfural to furfuryl alcohol. The reaction was conducted under an optimized condition (furfural (10 mmol), triethylamine $\left(\mathrm{Et}_{3} \mathrm{~N}\right)(10 \mathrm{mmol})$, formic acid $(20 \mathrm{mmol})$, temperature $\left(160^{\circ} \mathrm{C}\right)$, catalyst amount $\left.(40 \mathrm{mg})\right)$ realizing a yield of 76.5\% and 100\% furfuryl alcohol using @PdCassCat and @PtCassCat, respectively. The catalytic activities of the @PdCassCat and @PtCassCat were excellent as well as recyclable up to four and five times, respectively.

Keywords: phytoextraction; platinum group metals; furfural; furfuryl alcohol; bio-ore; hydrogenation; heterogenous catalysts

\section{Introduction}

Ore exploitation and mining operations of precious metals such as platinum group metals (PGMs) have been carried out since the emergence of civilization, contributing significantly to the development of mankind [1]. This process has dire environmental consequences especially when conducted through conventional mining techniques (most often via underground, open surface (pit), placer, and in-situ method) [2]. Mining in South Africa contributes tremendously to the socio-economic development, with regard to the actual minerals being extracted and in the creation of job opportunities [3]. Notwithstanding, the aftermath of this operation include environmental disruptions that cause land/soil pollution, health, and safety concerns [4].

Plant-based technology like phytomining, could portray an innovative environmentally friendly cheap technology for the selective recovery of these precious metals in not only complementing the existing technological approach but also restoring the lost vitality to the ecosystem [5,6]. Various high biomass plant species termed hyperaccumulators [7-9], have been tested in the past mostly at the laboratory and/or pilot scale level for valuable metals (like gold $(\mathrm{Au})$, nickel $(\mathrm{Ni})$ ) recovery [6,8]. But these reports have shown that most precious metals like palladium $(\mathrm{Pd})$ and platinum $(\mathrm{Pt})$ are non-bioavailable to 
plants $[8,10,11]$; as such, usually being aided by chemical amendment method-lixiviants (such as potassium cyanide, potassium bromide, thiocyanate, and ammonium thiosulfate to mention few) [11,12]. Nevertheless, the costs of phytoextraction coupled with lixiviants to smelting process stage may not be financially appealing. Besides, the detrimental effects associated with cyanide application in the environment can never be overemphasized.

The possibility of natural metal accumulating plants like cassava (Manihot esculenta) releasing metal-chelating agents (cyanogens) to the rhizosphere, which act to solubilize and thereafter chelate with the target metals strongly bound to the soil have been proven to be profitable $[13,14]$. The potential of these plants to form metallic nanoparticles (NPs) as an outcome of phytomining could make the recouped metal ideally suitable for utilization in green chemical technologies, like catalysis [15]. So far two studies have demonstrated this $[12,16]$, using chemical amendments (cyanides). To this end, there is a need to develop a field suitable, high biomass natural hyperaccumulators to extract PGMs and produce a plant-based catalyst for use in green chemical reactions.

The global utilization of non-renewable fossil fuels and petrochemicals is rapidly overwhelming leaving the earth's fixed resources at a constant depleting rate [17]. It is difficult to appraise their depletion rate, which is the key source of carbon-based building blocks; the environmental and sustainability issues have inspired growing attention to the understanding and application of alternative basic chemicals [18]. The use of lignocellulosic biomass for the formulation of biofuels is attracting attention from industrial and scientific corners; and furfural, (a main component in bio-oil) is one of the many intermediate derivatives that can be obtained from renewable biomass for the production of different important fine chemicals [19]. Subject to the catalyst being used, hydrogenation of furfural can generate a wide range of industrially important chemicals, for example, furfuryl alcohol, 2-methylfuran, furan, cyclopentanone, tetrahydrofurfuryl alcohol [20-22]. Of these chemicals, furfuryl alcohol is the most popular.

Until now, the commercial production of furfuryl alcohol from furfural has been achieved via copper chromite-catalyzed reaction under harsh operating conditions [23,24], not to mention the utilization of the toxic chromium $(\mathrm{Cr})$ with serious environmental issues (associated with the preparation, handling, and disposal) $[25,26]$. In the past, precious metal catalysts such as supported $\mathrm{Pd}$ and $\mathrm{Pt}$ have been reported to be active in aqueous phase hydrogenation of furfural [27-29]. However, the scarce nature and the competitive cost is a key set back to the use of these valuable metals. For this reason, it is pertinent to develop a cost-effective and environmentally benign catalyst that could efficiently and selectively convert furfural to furfuryl alcohol in mild condition. Herein, we described the hydrogenation of furfural to furfuryl alcohol with cheap, environmentally friendly bio-ore catalysts sourced from pilot scale phytomining experiment conducted in the green house.

\section{Experimental}

\subsection{Materials and Chemicals}

All reagents/chemicals used throughout the method development were of analytical grade and high-purity de-ionized water $\left(18.2 \mathrm{M} \Omega \mathrm{cm}^{-1}\right)$ (Millipore Milli-Q, Bedford, Boston, MA, USA) was used for dilution of the standards, preparation of samples, and for rinsing the glassware after soaking in $10 \%$ nitric acid $\left(\mathrm{HNO}_{3}\right)$ for $24 \mathrm{~h}$. The $\mathrm{HNO}_{3}(65 \%$, Suprapur $^{\circledR}$, Merck, Darmstadt, Germany), hydrochloric acid (HCl) (37\%, Sigma-Aldrich, Burlington, MA, USA), and hydrofluoric acid (HF) (40\%, AAR grade, SMM Instruments, Johannesburg, South Africa), were utilized for digestion of samples. Palladium chloride, and potassium tetrachloroplatinate (II) were purchased from Sigma-Aldrich (Johannesburg, South Africa) and were all used as received for contamination purpose. Both stock standards used during inductively coupled plasma-optical emission spectrometry (ICPOES) analysis including Pd and Pt were ICP-standard grade, containing $1000 \mathrm{mg} / \mathrm{L}$ stock solutions in 2\%-3\% $(v / v) \mathrm{HNO}_{3}$ were obtained from Merck, Germany and used for the preparation of calibration standards. Furfural, triethylamine, formic acid, potassium hydroxide $(\mathrm{KOH})$, pyridine, deuterated chloroform $\left(\mathrm{CDCl}_{3}\right)$, and dimethylformamide (DMF) 
were also purchased from Sigma-Aldrich (Johannesburg, South Africa) and used as received for catalysis purpose. In all the experimental operations, the repeatability and reproducibility were conducted in triplicates starting from growing the cassava plant till catalysis performance test.

\subsection{Plant Growth}

The Manihot esculenta was grown from the cuttings of stem on a rich compost potted mix soil in the Department of Botany, University of Johannesburg, Auckland Park, South Africa. After maturity, the plant was re-propagated in the greenhouse section of the department in twelve different $25 \mathrm{~L}$ plastic pots containing the same rich loamy compost soil. The plants were watered in every two days interval and the growth was monitored. The glasshouse temperatures were controlled between $14^{\circ} \mathrm{C}$ (night) and $25^{\circ} \mathrm{C}$ (day). The cooling system was initiated at temperature above $27^{\circ} \mathrm{C}$ in the day and above $20^{\circ} \mathrm{C}$ at night. After sufficient growth was observed for a period of six months, five in each case of the potted plants were contaminated with $500 \mathrm{mg} / \mathrm{L}$ of Pt and Pd solutions intermittently for eight weeks (a liter per week). The other two potted cassava plants were used as control system, with continual watering using tap water. At the end of the eighth week, all the plants were harvested, thoroughly rinsed, cut into parts/organs (leaves, stems and root), dried under room temperature and finally crushed and grinded to a powder using NIMA electric grinder (Japan) and an agate mortar and pestle. The mixture was thereafter stored in brand new $50-\mathrm{mL}$ centrifuge plastic tubes until analysis.

A $0.5 \mathrm{~kg}$ composite representative soil sample in each case was taken equally from each potting mix, dried separately, ground, and stored in a new centrifuge bottle until analysis.

\subsection{Digestion Procedures}

A $0.1 \mathrm{~g}$ of plant sample was accurately weighed into a dry microwave digestion vessel. A $6.0 \mathrm{~mL}$ of $37 \% \mathrm{HCl}$ as well as $2.0 \mathrm{~mL}$ of $65 \% \mathrm{HNO}_{3}$ was added slowly to the vessel. The vessels were closed and mounted to the CEM Corporation MARS 6 microwave digestion system (CEM Corp., Matthews, Nelson, New Zealand) for digestion according to the following heating pattern: (i) Ramping for 25 min with maximum control pressure and power of $800 \mathrm{psi}$ and $1800 \mathrm{~W}$, respectively; (ii) holding at maximum temperature of $200{ }^{\circ} \mathrm{C}$ for $10 \mathrm{~min}$, and subsequent cooling to $55^{\circ} \mathrm{C}$. A set of six reagent blanks in each case were prepared with each batch of the sample containing all the reagents excluding the plant and soil samples. Subsequently, the vessels were evacuated, cooled in the fume hood, and vented gradually so as to let off the built pressure.

For soil samples, $0.1 \mathrm{~g}$ of the sample was acid-digested using a blend of $6.0 \mathrm{~mL} 37 \%$ $\mathrm{HCl}, 2 \mathrm{~mL} 65 \% \mathrm{HNO}_{3}$, and $2 \mathrm{~mL} 40 \% \mathrm{HF}$ in a high-pressure microwave system following a previously reported method [30]. Finally, the resulting clear digested sample solutions were let to cool to room temperature in the fume hood, the cooled solutions were then filtered using $0.45 \mu \mathrm{m}$ membrane filters (Sigma Aldrich, Burlington, MA, USA), quantitatively transferred to $50 \mathrm{~mL}$ volumetric flask, and diluted up to the mark with ultrapure water. Solutions were then analyzed by inductively coupled plasma-optical emission spectrometry (ICP-OES) using a Spectro Arcos ICP-OES FSH-12 instrument (Analytik, Jena, Germany). Details of the instrumental operating conditions are shown in Table 1.

\subsection{Formation of the Catalyst}

In order to produce the catalyst, ground plant samples with highest concentration (root) was calcinated/bio-charred using 909 Scientific Furnace (Lenton Furnaces, Sheffield, UK) at $300{ }^{\circ} \mathrm{C}$ under air as previously described with slight modifications [16].

\subsection{Digestion of Calcinated Plant Samples}

The resulting bio-ore samples from both contaminated (Catalyst-@PdCassCat \& @PtCassCat) and control biomass samples were digested following the same method as described above for digestion of plant samples. 
Table 1. Operating conditions of ICP-OES.

\begin{tabular}{cc}
\hline Parameters & Setting \\
\hline RF generator power & $1400 \mathrm{~W}$ \\
Generator of radio frequency & $40 \mathrm{MHz}$ \\
Plasma argon flow rate & $12.02 \mathrm{~L} / \mathrm{min}$ \\
Auxiliary argon flow rate & $1.00 \mathrm{~L} / \mathrm{min}$ \\
Nebulizer argon flow rate & $0.80 \mathrm{~L} / \mathrm{min}$ \\
Sample uptake rate & $1.00 \mathrm{~mL} / \mathrm{min}$ \\
Inner diameter of the torch injector & $2.00 \mathrm{~mm}$ \\
Nebulizer type & Perkin-Elmer cross flow \\
Type of spray chamber & Double pass Scott spray chamber \\
Measurement replicates & 3 \\
Element & Pd 340.458 nm \\
& Pt 214.423 nm \\
\hline
\end{tabular}

\subsection{Catalyst Characterization}

To determine the internal structure, surface morphology, elemental composition, and particle size of the samples, transmission electron microscopy (TEM) and scanning electron microscopy (SEM) analysis were performed using high resolution transmission electron microscope (HRTEM: JEOL-JEM-2100F, JEOL Ltd., Tokyo, Japan) with an accelerating voltage of $200 \mathrm{kV}$ and scanning electron microscope (VEGA 3 TESCAN, Brno, Czech) coupled with an energy dispersive X-ray (EDX) analyzer with a high voltage of $20 \mathrm{kV}$, respectively. For TEM analysis sample preparation, both the catalyst and the control samples were ultrasonically suspended in ethanol and a solution drop was deposited onto the copper $(\mathrm{Cu})$ grid. The solvent was allowed to evaporate before being mounted to the instrument. Particle sizes were determined by analyzing HRTEM images obtained by ImageJ software. Prior to SEM analysis, the samples were carbon-coated on an aluminum plate using Quorum Q300T (Quorum Technologies, Lewes, UK) carbon coater system.

The pXRD analysis was performed on a PANanalytical X'perto PRO X-Ray diffractometer (Malvern PANalytical Ltd, Almelo, The Netherlands) equipped with $\mathrm{Cu} \mathrm{K} \alpha 1$ radiation source $(\lambda=0.154 \mathrm{~nm})$. X-ray patterns were recorded in a range from 4 and $90\left({ }^{\circ} 2 \theta\right)$ with a scan speed of $0.0244^{\circ} / \mathrm{s}$ and step size $0.0167\left({ }^{\circ} 2 \theta\right)$. The UV - Vis spectra were obtained with a Shimadzu UV1800 spectrophotometer (Japan) using ethanol as blank.

For nitrogen adsorption-desorption isotherms examined using a Belsorp-max, the mean pore diameter, pore volume, and surface area were estimated using Brunauer-Emmett-Teller (BET) and Barrett-Joyner-Halenda (BJH) techniques (Micromeritics ASAP 2460, Micromeritics Instruments Corporation, Norcross, GA, USA). Before the experiment, the samples were degassed at $90^{\circ} \mathrm{C}$ for $18 \mathrm{~h}$.

\subsection{Catalytic Reactions}

2.7.1. Catalytic Reaction Procedure for Transfer Hydrogenation Reaction

The catalytic tests were performed following the method as described by Moyo et al. [31], with slight modification. In a typical experiment, a substrate- furfural $(10 \mathrm{mmol})$, a base (triethylamine) $(10 \mathrm{mmol})$, catalyst (20 mg: $1.46 \times 10^{-5} \mathrm{mmol}$ of $@$ PdCassCat and $4.74 \times 10^{-4} \mathrm{mmol}$ for $@$ PtCassCat), and hydrogen source, formic acid (20 mmol), were sequentially placed into a $50 \mathrm{~mL}$ autoclave reactor. The temperature was set for the needed length of time with a stirring speed of $1000 \mathrm{rpm}$ and the reaction mixture was heated accordingly after purging five times with nitrogen $\left(\mathrm{N}_{2}\right)$ gas. Subsequently, the reactor vessel was cooled, and the built pressure was released through the reactor valve. A portion $(50 \mu \mathrm{L})$ from the content was thereafter analyzed by ${ }^{1} \mathrm{H}$ NMR spectroscopy.

\subsubsection{NMR Studies}

The ${ }^{1} \mathrm{H}$ NMR spectra were recorded on a Bruker Ultrashield $500 \mathrm{MHz}$ spectrometer in chloroform. The spectrometer values were reported relative to the internal standard 
dimethylformamide $(\delta 0.00)$. All chemical shifts were reported in ppm. The conversion of furfural was calculated as follows:

$$
\text { Conversion }(\%)=\frac{\mathrm{mmol} \text { of furfural converted }}{\mathrm{mmol} \text { of furfural fed }} \times 100 \%
$$

\subsubsection{Catalyst Recycling Study}

The reusability of the catalyst was carried out based on the method described by Wu et al. [32], with slight modification. The @PdCassCat and @PtCassCat catalyst were filtered, washed five times with ethanol, dried at $80^{\circ} \mathrm{C}$ under $\mathrm{N}_{2}$ for $12 \mathrm{~h}$, and thereafter, reused at the same reaction conditions. To validate the repeatability and reproducibility of the results, the test was repeated in triplicates and the average values were taken.

\section{Results and Discussion}

Both subject and control plants for Pd and Pt trials grew significantly for the period of six months until contamination of the subjects began. Compared to the control (Figure 1a), visible phytotoxic appearance was observed at the end of the fifth week (Figure 1b) of contamination resulting in yellowish leaves, clear necrosis/chlorosis, which prolonged to the final death of the plants at eighth week (Figure 1c). The undertaken plants took up both $\mathrm{Pd}$ and $\mathrm{Pt}$ metals. The average concentrations of $\mathrm{Pd}$ and $\mathrm{Pt}$ in the soil and plant organs (leaves, stems and roots) of Manihot esculenta plant are presented in Tables 2 and 3. In both experiments, the roots contained the highest concentration of $\mathrm{Pd}(78 \pm 0.047 \mu \mathrm{g} / \mathrm{g})$ and $\mathrm{Pt}(1276 \pm 0.036 \mu \mathrm{g} / \mathrm{g})$. The Pd contents in leaves and stem portions of the contaminated plants, however, displayed lower concentrations of $\mathrm{Pd}$, lesser than the limit of detection (LOD) $(0.0026 \mu \mathrm{g} / \mathrm{g})$ as well as that from the control plant. The Pt concentration was higher in the leaves $(264 \mu \mathrm{g} / \mathrm{g})$ compared to the stem $(106 \mu \mathrm{g} / \mathrm{g})$. As usual, those found in the control plants were lower than the concentration revealed by the LOD $(0.036 \mu \mathrm{g} / \mathrm{g})$. Though there may not be practical evidence to support the differing rate of natural metal uptake and translocation pace since both subject plants were exposed to the same greenhouse conditions and individual metal concentrations $(500 \mathrm{mg} / \mathrm{L})$. However, the results of this study has further corroborated the hypothesis that PGMs are extensively accumulated in the roots and partly transported to shoots (leaves) [33-35]. Similarly, Alcantara et al. [13] reported same trend in the fibrous roots of cassava grown on mercury $(\mathrm{Hg})$ and $\mathrm{Au}-$ containing mixture of biosolids and mine tailings.
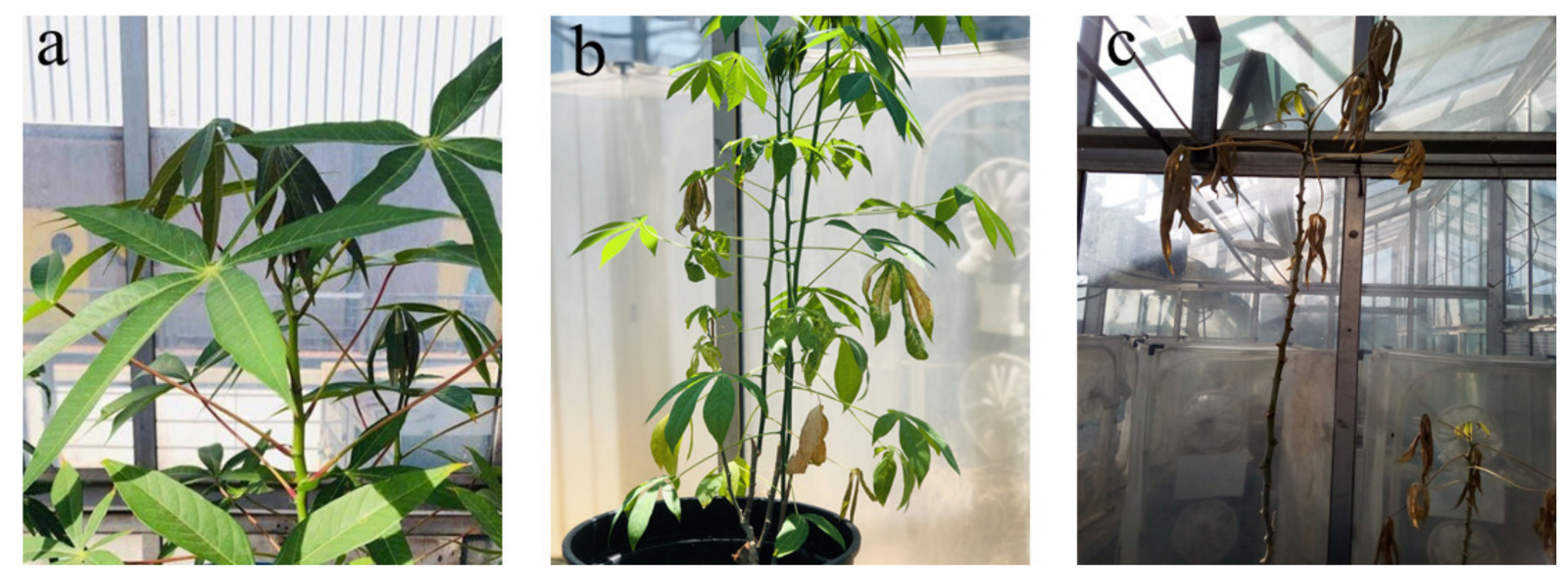

Figure 1. Representative cassava plant samples at various stages (a) control/uncontaminated sample (b) fifth week period and (c) at eighth week period of contamination.

Figure 2a,b shows the TEM and HRTEM images of both @PtCassCat and @PdCassCat, respectively confirming the presence of $\mathrm{Pt}$ and $\mathrm{Pd}$ nanoparticles. The micrographs revealed highly dispersed spherical Pt and Pd (NPs) anchored on the carbonaceous support in both catalysts desirable for catalysis applications. Further examination using image J software 
represented by upper histogram (Figure 2(a2,b2)) of @PtCassCat and @PdCassCat showed the particle size distributions in the range of 1-12 $\mathrm{nm}$ with an average particle size of $3.2 \pm 1 \mathrm{~nm}$. The control sample (Figure 2(c1,c2)) however displayed a darker amorphous layer of carbon support as there were no deposited metal on the surface.

Table 2. Total concentrations of Pd in the calcinated cassava plant organs and soil.

\begin{tabular}{cccc}
\hline Plant Organs & Amount Uptake $(\mu \mathrm{g} / \mathrm{g})$ & Percentage Uptaken & Control \\
\hline Leaf & $\leq 0.0026$ & $\leq 0.0026$ & $\leq 0.0026$ \\
Stem & $\leq 0.0026$ & $\leq 0.0026$ & $\leq 0.0026$ \\
Adventitious root & $78 \pm 0.047$ & 22 & $\leq 0.0026$ \\
Soil & $356 \pm 0.091$ & - & $\leq 0.0326$ \\
\hline Total Uptaken by Plant & $78 \pm 0.047$ & $22 \%$ & \\
\hline
\end{tabular}

"_": Not applicable.

Table 3. Total concentrations of Pt in the calcinated cassava plant organs and soil.

\begin{tabular}{cccc}
\hline Plant Organs & Amount Uptake $(\mu \mathrm{g} / \mathrm{g})$ & Percentage Uptaken $(\%)$ & Control \\
\hline Leaf & $264 \pm 0.071$ & 11 & $\leq 0.036$ \\
Stem & $106 \pm 0.005$ & 4.4 & $\leq 0.036$ \\
Adventitious root & $1276 \pm 0.035$ & 53 & $\leq 0.036$ \\
Soil & $2408 \pm 0.046$ & - & $\leq 0.042$ \\
\hline Total Uptaken by Plant & $1646 \pm 0.111$ & 68.4 & \\
\hline
\end{tabular}

"_": Not applicable.
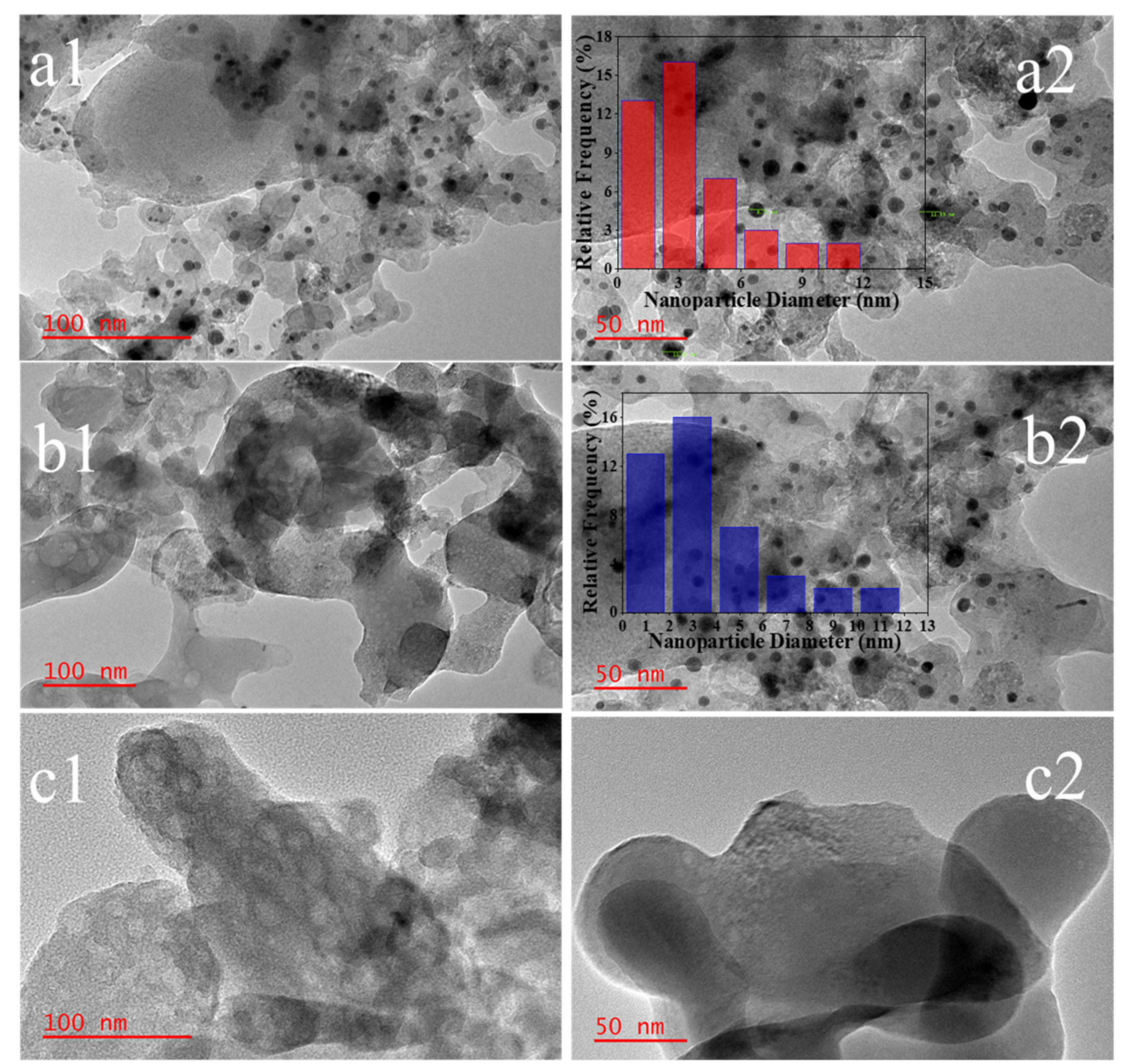

Figure 2. TEM/HRTEM micrograph of Pt and Pd nanoparticles in the Biochar of (a1,a2) @PtCassCat, $(\mathbf{b} 1, \mathbf{b} 2) @$ PdCassCat and (c1,c2) control biochar sample. 
The SEM micrographs of @PdCassCat and @PtCassat (Figure 3a,b) revealed their porous structure comprising of networks of irregular block rough surface linked with hollow structures, which allow rapid diffusion of the catalyst in and out of the surface compared to the control with closed surface structure (Figure 3c) indicating the absence of both Pd and Pt as shown on the EDX micrograph (Figure 3d).

The EDX mapping images (Figures 4 and 5) confirm that the Pd and Pt metals were homogeneously dispersed in the carbonaceous support. The signal from Pd and Pt was detected throughout the entire catalysts in each case which shows that Pd and Pt particles were incorporated inside the @PdCassCat and @PtCassCat surface. Other elemental components captured on the mapping including calcium (Ca), sulfur $(\mathrm{S})$, magnesium $(\mathrm{Mg})$, sodium $(\mathrm{Na})$, phosphorous $(\mathrm{P})$, oxygen $(\mathrm{O})$, carbon $(\mathrm{C})$, and potassium $(\mathrm{K})$ are all part of essential minerals chiefly found in plants.
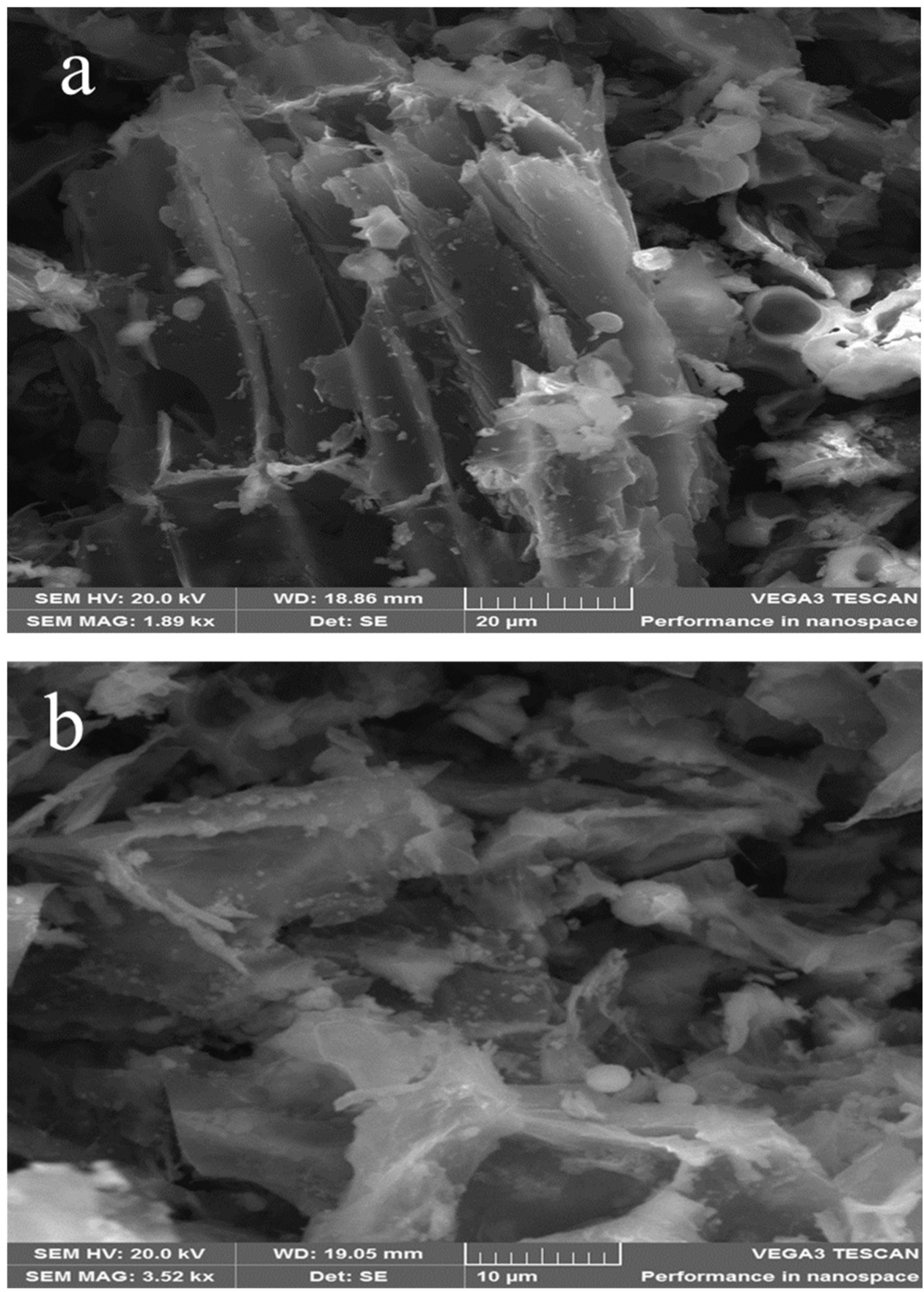

Figure 3. Cont. 

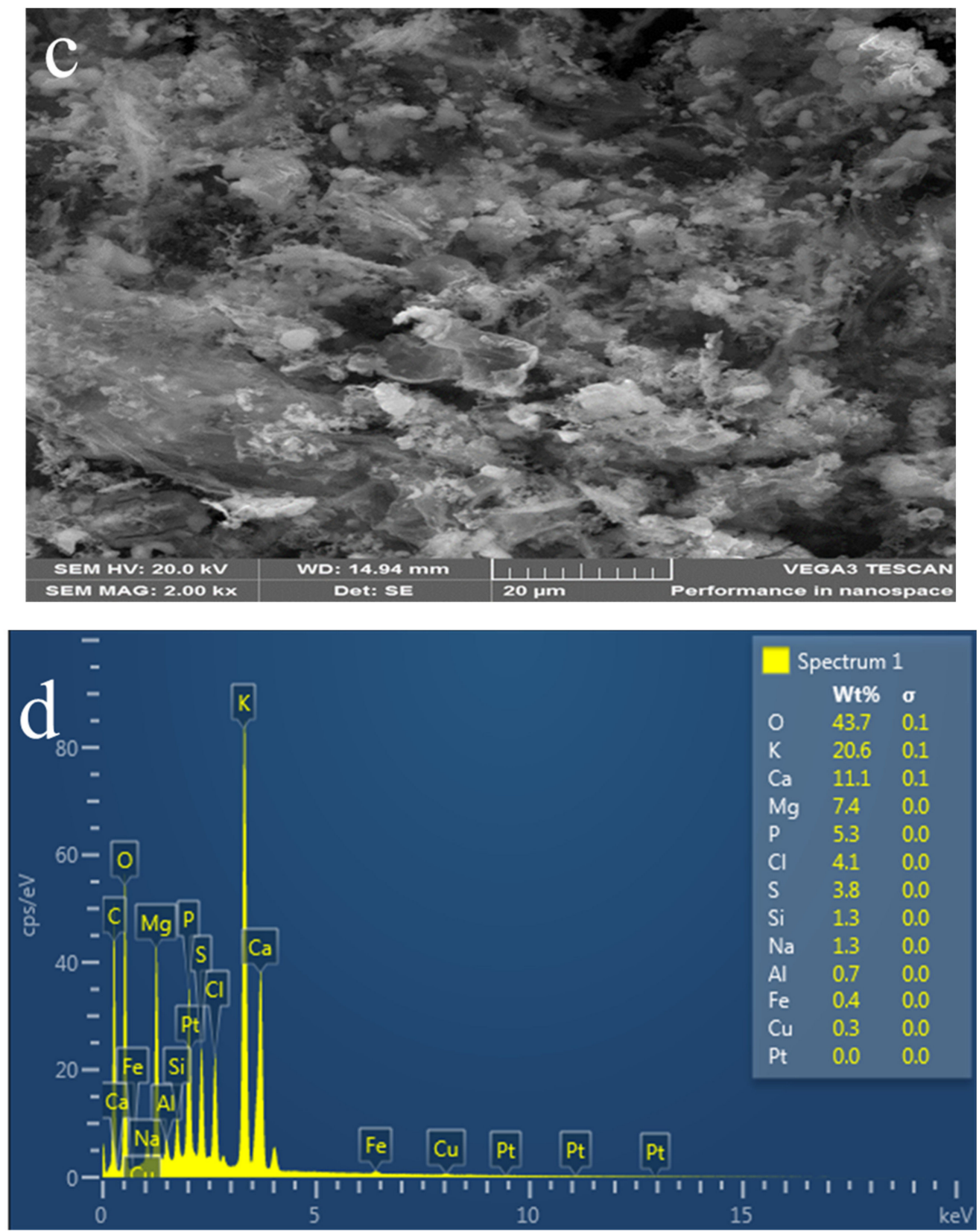

Figure 3. SEM micrographs of the biochar of (a) @PdCassCat, (b) @PtCassCat, (c) control sample, and (d) EDX of the control.

The pXRD of @PdCassCat along with pure $\mathrm{PdCl}_{2}$ and @PtCassCat with $\mathrm{K}_{2} \mathrm{PtCl}_{4}$ are shown in Figure 6a,b, respectively. The obtained diffractograms depict the crystallinity of the catalysts. The XRD analysis of the @PdCassCat indicated the characteristic diffraction peaks of pure crystalline Pd nanoparticles found at $2 \theta$ values of $40.1^{\circ}$, and $81.5^{\circ}$. The observed peaks correspond to the lattice planes (111) and (311) indexed to a face central cubic structure. These are in agreement with the values reported for face-centered cubic of Pd NPs [36,37]. This further confirmed that the biochar catalyst contains Pd NPs corroborating the TEM report. Similarly, the XRD pattern shown in Figure $6 \mathrm{~b}$ confirms the formation of Pt NPs. The diffraction peaks of @PtCassCat found at $2 \theta$ values of $39.82^{\circ}$, $46.22^{\circ}$ are consistent with (111) and (200) crystalline planes, respectively specifying a single-phase $\mathrm{Pt}$ with a face-centered cubic structure. 

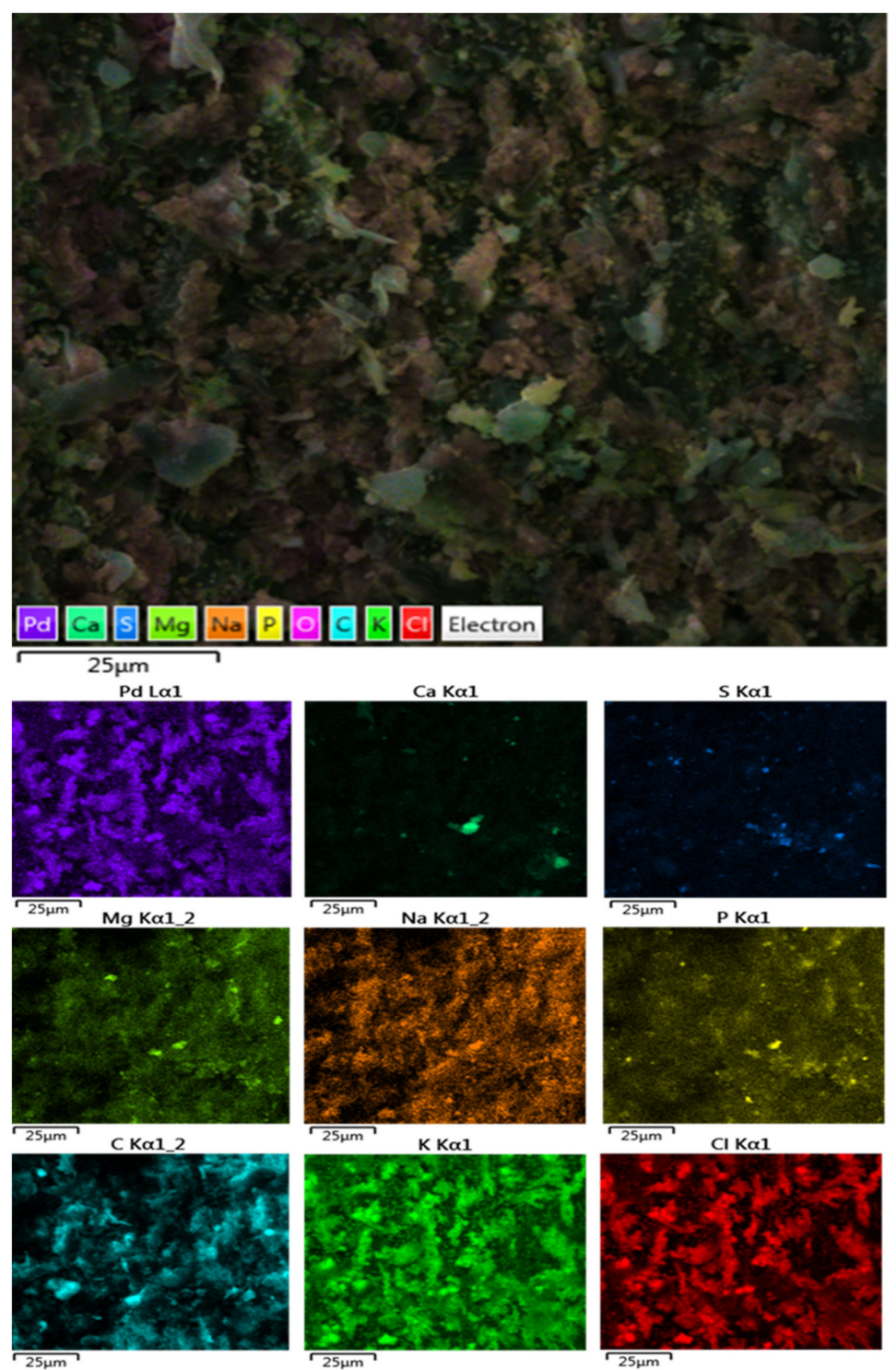

Figure 4. EDX mapping images of @PdCassCat.

To further validate the chemical states of $\mathrm{Pd}$ and $\mathrm{Pt}$ species in the bio-ore, UV-Vis analysis were carried out. Figure 7a-c shows UV-visible spectra of Pd and Pt NPs and their precursors $\left(\mathrm{PdCl}_{2}\right.$ and $\left.\mathrm{K}_{2} \mathrm{PtCl}_{4}\right)$. The $\mathrm{UV}$-visible spectrum of the $\mathrm{PdCl}_{2}$ (Figure $7 \mathrm{a}$ ) shows a distinct absorption band at $426.5 \mathrm{~nm}$ due to the absorption of $\mathrm{Pd}^{2+}$ ions [38,39]. These peaks were absent in the catalyst (@PdCassCat) indicating the complete reduction of $\mathrm{Pd}^{2+}$ to $\mathrm{Pd}^{0}$ (NPs). This value is in agreement with literature reports on green synthesis of Pd NPs from $\mathrm{PdCl}_{2}$ [36,40-42]. Figure 7c shows the UV-visible spectrum of the reduced platinum tetrachloride that was used to prepare a solution for artificial contamination of the plant. For @PtCassCat, the peak at wavelength $485 \mathrm{~nm}$ found on the $\mathrm{K}_{2} \mathrm{PtCl}_{4}$ (Figure $7 \mathrm{~b}$ ) was absent; instead, a flat continuous absorption was observed, indicating the complete reduction of $\mathrm{Pt}^{2+}$ ions to $\mathrm{Pt}^{0}$ (Pt NPs). This result agrees with previous literature reports [43]. The issue of nanoparticle accumulation by plants is very complex. However, it has been proposed that nanoparticles source in plant could either be through: direct accumulation of nanoparticles or reduction of metal ions taken up [44,45]. We hypothesized that cyanogen-rich plants like cassava as used herein are capable of exuding their cyanides, that complexed with $\mathrm{Pd}^{2+}$ and $\mathrm{Pt}^{2+}$ in the soil through the root cell walls, where reduction occurs and thus resulting in a lesser amount being available for transport to the aerial parts of the plant. 

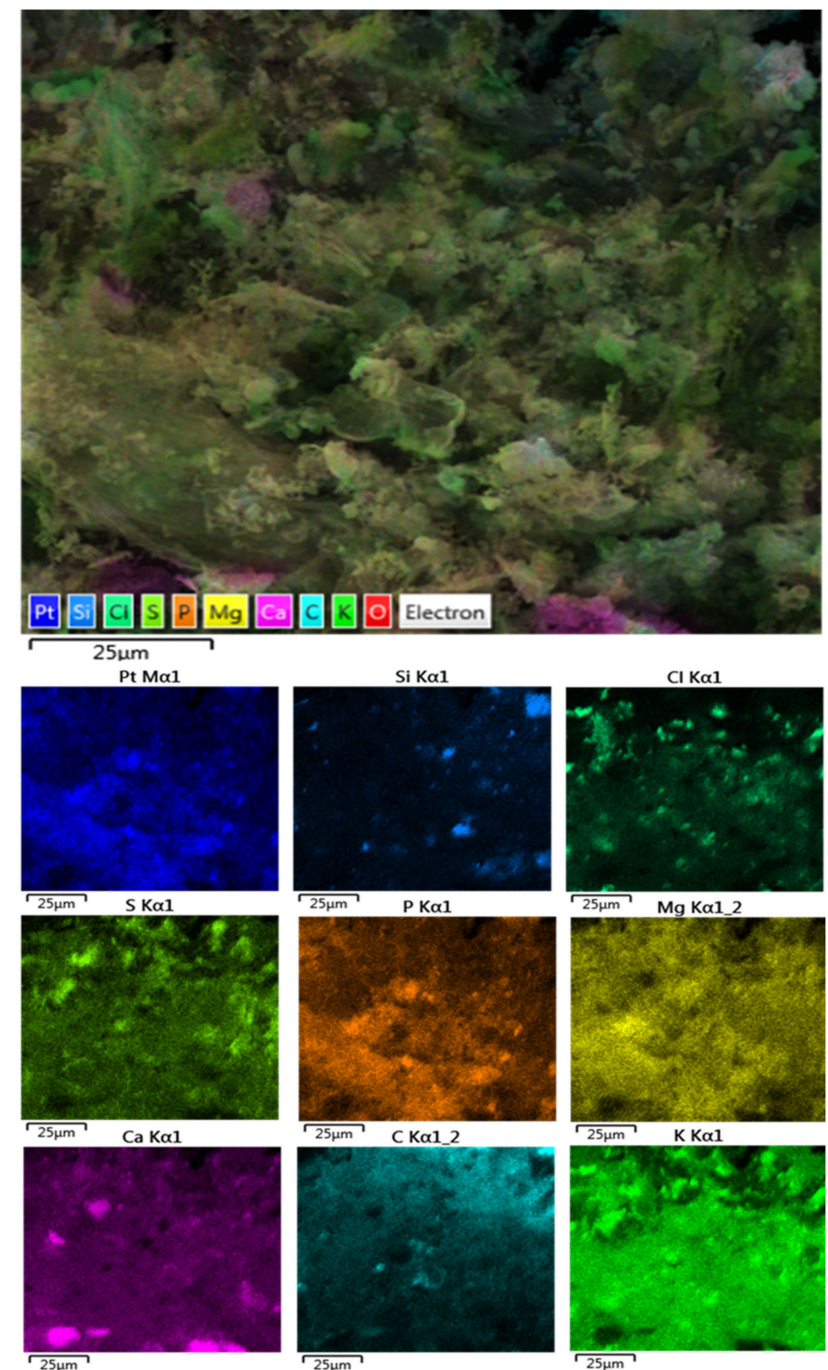

Figure 5. EDX mapping images of @PtCassCat.
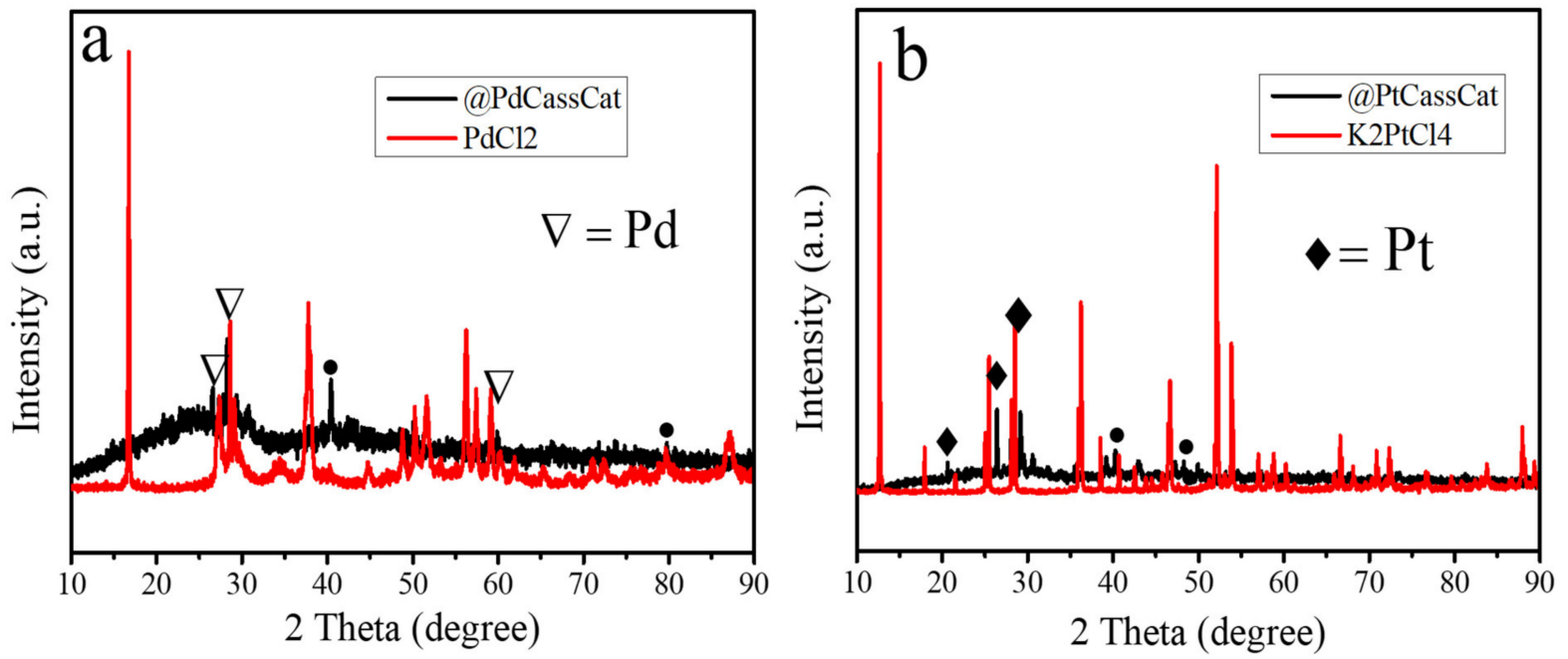

Figure 6. pXRD diffraction patterns of (a) @PdCassCat and $\mathrm{PdCl}_{2}$ and (b) @PtCassCat and $\mathrm{K}_{2} \mathrm{PtCl}_{4}$. 

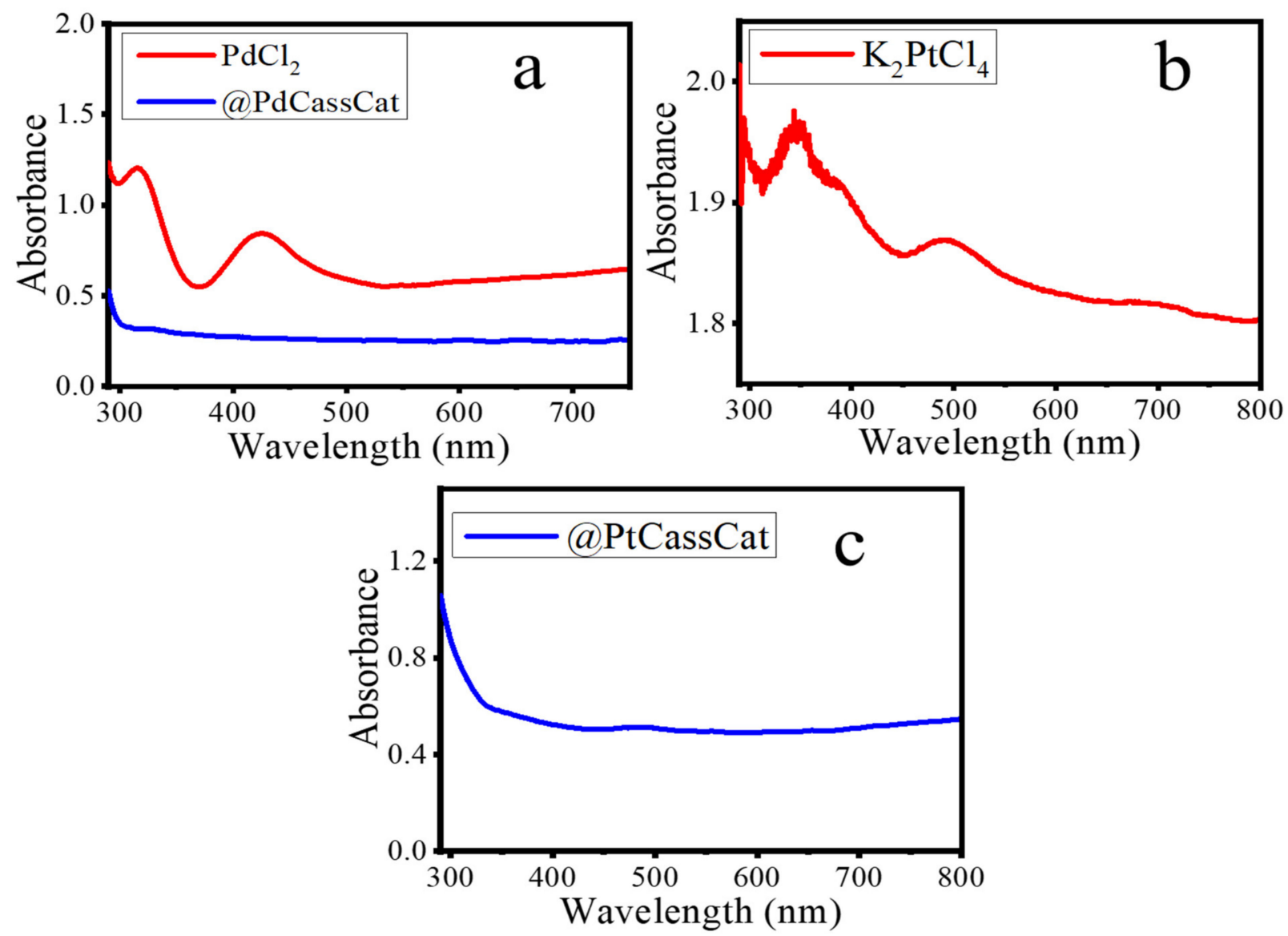

Figure 7. UV-Vis absorption spectra of (a) $\mathrm{PdCl}_{2}$ and Pd NPs in @PdCassCat (b) $\mathrm{K}_{2} \mathrm{PtCl}_{4}$ and (c) Pt NPs in @PtCassCat.

Table 4 and Figure 8 depict the textural features and adsorption/desorption isotherm curves of the two catalysts, @PdCassCat, @PtCassCat and their control biochar samples. As shown in Figure 8a,b, both catalysts showed larger pores mostly within the mesoporous range characteristic of type IV isotherm [46] with a high surface area (of 4.92 and $12.5 \mathrm{~m}^{2} / \mathrm{g}$ for @PdCassCat and @PtCassCat, respectively) compared to the control sample $\left(3.96 \mathrm{~m}^{2} / \mathrm{g}\right)$. Similarly, both catalysts have H3 type hysteresis loops [47], according to International Union of Pure and Applied Chemistry (IUPAC) classification, indicating the presence of "slit pores" from layered aggregates. The incorporation of $\mathrm{Pd}$ and $\mathrm{Pt}$ into the biomatrix could be the reason for the increased pore size and surface areas on the path of both catalysts. This facilitates catalysts dispersion and invariably may relieve the reactants and products diffusion limitations in the process.

Table 4. Physicochemical characteristics of @PtCassCat, @PdCassCat, and control biochar sample.

\begin{tabular}{|c|c|c|c|c|}
\hline Sample & $\mathrm{S}_{\text {BET }}\left(\mathrm{m}^{2} / \mathrm{g}\right)$ & Pore Volume $\left(\mathrm{cm}^{3} / \mathrm{g}\right)$ & Pore Diameter (nm) & Metal Loading ${ }^{*}(w t \%)$ \\
\hline @PtCassCat & 12.50 & 0.933 & 30.39 & 0.24 \\
\hline$@$ PdCassCat & 4.92 & 0.579 & 29.70 & $7.8 \times 10^{-3}$ \\
\hline Control & 3.96 & 0.560 & 28.40 & 0 \\
\hline
\end{tabular}



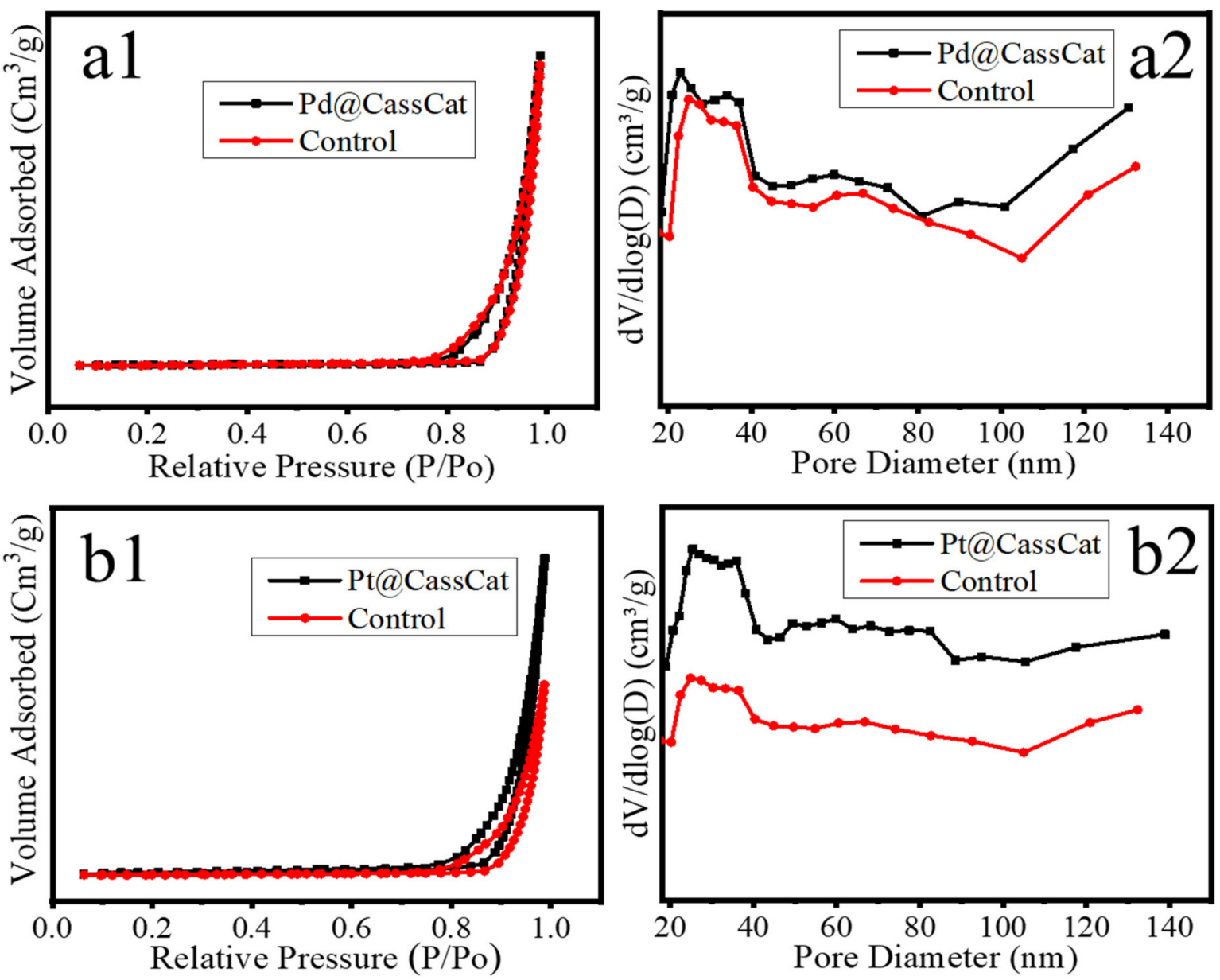

Figure 8. $\mathrm{N}_{2}$ adsorption-desorption isotherms of (a1) @PdCassCat, (b1) @PtCassCat and control, and BJH pore size distribution of (a2) @PdCassCat, (b2) @PtCassCat, and control sample.

\subsection{Catalysis: Transfer Hydrogenation of Furfural}

\subsubsection{Catalytic Activity of @PdCassCat and @PtCassCat}

Having characterized the catalysts, the catalytic activity in the transfer hydrogenation of furfural to furfuryl alcohol was then evaluated. Effect of different bases, temperature variations, catalyst loading, and reaction times were investigated (Table 5). The choice of formic acid as hydrogen source was based on the previously established method [31]. Foremost, the catalytic activity of the @PdCassCat was tested using three bases namely: potassium hydroxide $(\mathrm{KOH})$, pyridine, and triethylamine over a $24 \mathrm{~h}$ period (Figure 9). Of the three employed bases, only triethylamine yielded product with conversion of $44.5 \%$ at a fixed temperature of $140{ }^{\circ} \mathrm{C}$. Similar trend was observed by Moyo and coworkers who studied the mechanism of $\mathrm{Pd}(\mathrm{II})$ - and $\mathrm{Pt}(\mathrm{II})$-catalyzed selective synthesis of furfuryl alcohol [31]. Thereafter, the performance of @PtCassCat catalyst was checked in triethylamine base (Table 5, entry 4) under the same condition $\left(20 \mathrm{mg}\left(2.47 \times 10^{-4} \mathrm{mmol}\right)\right.$, $\left.160{ }^{\circ} \mathrm{C}, 24 \mathrm{~h}\right)$. Apparently, @PtCassCat showed high catalytic activity with $100 \%$ conversion (Figure S1). When compared with @PdCassCat $(0.0078$ wt $\%)$, it could be said that the total conversion experienced with Pt catalyst may be due to higher catalyst loading $(0.24 \mathrm{wt} \%)$. 
Table 5. Hydrogenation of furfural to furfuryl alcohol.

\begin{tabular}{|c|c|c|c|c|c|c|c|c|}
\hline Entry & Catalyst & Base & $\begin{array}{c}\text { Temperature } \\
\left({ }^{\circ} \mathrm{C}\right)\end{array}$ & $\begin{array}{l}\text { Reaction } \\
\text { Time (h) }\end{array}$ & $\begin{array}{c}\text { Catalyst } \\
\text { Amount (mg) }\end{array}$ & $\begin{array}{c}\text { Conversion } \\
(\%)\end{array}$ & TON & TOF $\left(h^{-1}\right)$ \\
\hline 1 & @PdCassCat & $\mathrm{KOH}$ & 140 & 24 & 20 & 0 & 0 & 0 \\
\hline 2 & @PdCassCat & Pyridine & 140 & 24 & 20 & 0 & 0 & 0 \\
\hline 3 & $@$ PdCassCat & $\mathrm{Et}_{3} \mathrm{~N}$ & 140 & 24 & 20 & 44.5 & 305,358 & 25,446 \\
\hline 4 & @PtCassCat & $\mathrm{Et}_{3} \mathrm{~N}$ & 140 & 24 & 20 & 100 & 40,607 & 1692 \\
\hline 5 & $@$ PdCassCat & $\mathrm{Et}_{3} \mathrm{~N}$ & 100 & 24 & 20 & 9.4 & 64,384 & 2683 \\
\hline 6 & @PdCassCat & $\mathrm{Et}_{3} \mathrm{~N}$ & 120 & 24 & 20 & 34.1 & 233,762 & 9740 \\
\hline 7 & $@$ PdCassCat & $\mathrm{Et}_{3} \mathrm{~N}$ & 160 & 24 & 20 & 61.2 & 419,304 & 23,294 \\
\hline 8 & @PdCassCat & $\mathrm{Et}_{3} \mathrm{~N}$ & 160 & 24 & 10 & 2.3 & 31,369 & 1307 \\
\hline 9 & @PdCassCat & $\mathrm{Et}_{3} \mathrm{~N}$ & 160 & 24 & 30 & 57.1 & 258,447 & 10,769 \\
\hline 10 & @PdCassCat & $\mathrm{Et}_{3} \mathrm{~N}$ & 160 & 24 & 40 & 76.5 & 261,986 & 10,916 \\
\hline 11 & @PdCassCat & $\mathrm{Et}_{3} \mathrm{~N}$ & 160 & 24 & 50 & 71.9 & 196,986 & 8207 \\
\hline 12 & $@$ PdCassCat & $\mathrm{Et}_{3} \mathrm{~N}$ & 160 & 6 & 40 & 32.4 & 11,113 & 1852 \\
\hline 13 & @PtCassCat & $\mathrm{Et}_{3} \mathrm{~N}$ & 160 & 6 & 40 & 100 & 20,852 & 3475 \\
\hline 14 & @PdCassCat & $\mathrm{Et}_{3} \mathrm{~N}$ & 160 & 12 & 40 & 41.3 & 141,438 & 11,786 \\
\hline 15 & @PdCassCat & $\mathrm{Et}_{3} \mathrm{~N}$ & 160 & 18 & 40 & 73.2 & 250,684 & 13,927 \\
\hline
\end{tabular}

Reaction conditions: furfural $(10 \mathrm{mmol})$, base $(10 \mathrm{mmol})$, formic acid $(20 \mathrm{mmol})$, temperature $\left(100-160^{\circ} \mathrm{C}\right)$, time $(6-24 \mathrm{~h})$. Conversion is worked out by NMR spectroscopy using the previously stated equation; $\mathrm{TON}=\mathrm{mmol}$ of furfural $/ \mathrm{mmol}$ of catalyst; TOF $=\mathrm{TON} / \mathrm{time}$.

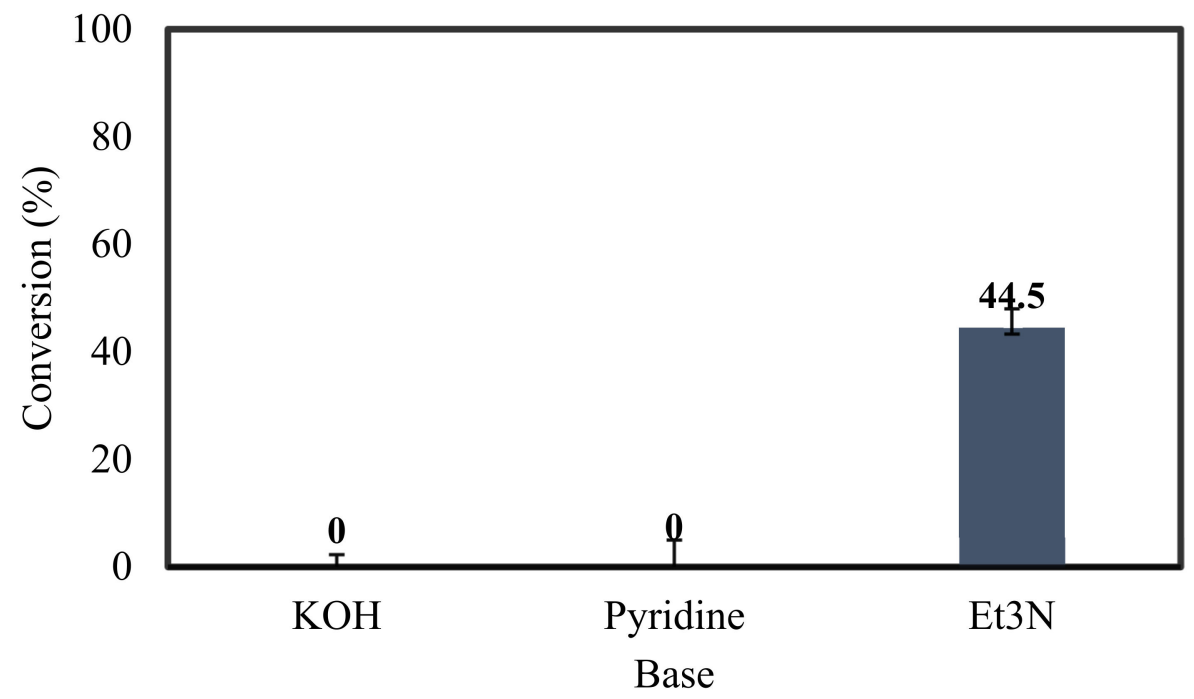

Figure 9. Conversion of furfural as a function of base. Conditions: furfural (10 mmol), base (10 mmol), formic acid (20 mmol), temperature $140{ }^{\circ} \mathrm{C}$, @PdCassCat catalyst amount $(20 \mathrm{mg})$, time $(24 \mathrm{~h})$.

Having established this, the influence of reaction temperature on furfural conversion was then examined (Figure 10). Noticeably, furfural conversion increased significantly from 9.4 through to $61.2 \%\left(100-160^{\circ} \mathrm{C}\right)$. Increasing the temperature favored more furfural conversion, however this may be economically unappealing considering the cost of energy. Besides, increasing reaction temperature may also provoke the dehydration of the product (alcohol) [48]. However, the activity is excellent when compared against laboratory synthesized non-conventional catalysts [49,50]. On this basis, it was concluded that furfural hydrogenation was favored at $160^{\circ} \mathrm{C}$.

With increasing catalyst (@PdCassCat) loading from 10, 20,30, to $40 \mathrm{mg}$, the conversion in $24 \mathrm{~h}$ increased as anticipated from $2.3 \%, 44.5 \%, 57.1 \%$, to $76.5 \%$, respectively (Figure 11 ). However, a diminution in conversion was observed when the loading was $50 \mathrm{mg}$. It is worthy to mention as determined by ICP-OES (Table 2) the infinitesimally low nature of Pd catalyst loading in our biochar $\left(20 \mathrm{mg} \sim 7.8 \times 10^{-3} \mathrm{wt} \%\right)$. Silva and co-workers used $2.0 \mathrm{wt} \%$ Pd catalysts supported on different hydrophilic or hydrophobic carbonaceous substrate for furfural conversion and achieved 75\% [51]. In this work, the amount of bio-ore 
catalyst precursor was more nearly hundred and thirty times less (40 $\mathrm{mg} \sim 0.0156 \mathrm{wt} \%$ ) but still gave a higher conversion $(76.5 \%)$ of furfural notwithstanding the longer duration.

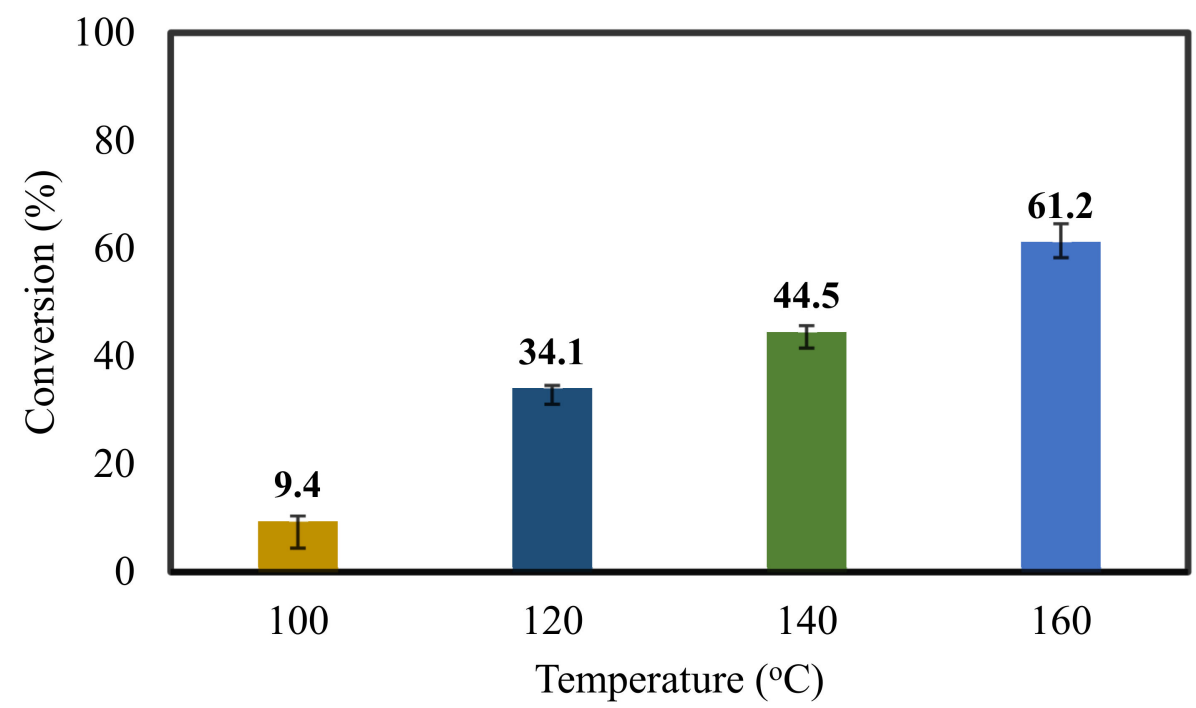

Figure 10. Influence of the reaction temperature on furfural conversion. Conditions: furfural $(10 \mathrm{mmol})$, base $\left(\mathrm{Et}_{3} \mathrm{~N}\right)(10 \mathrm{mmol})$, formic acid $(20 \mathrm{mmol})$, @PdCassCat catalyst amount $(20 \mathrm{mg})$, time $(24 \mathrm{~h})$.

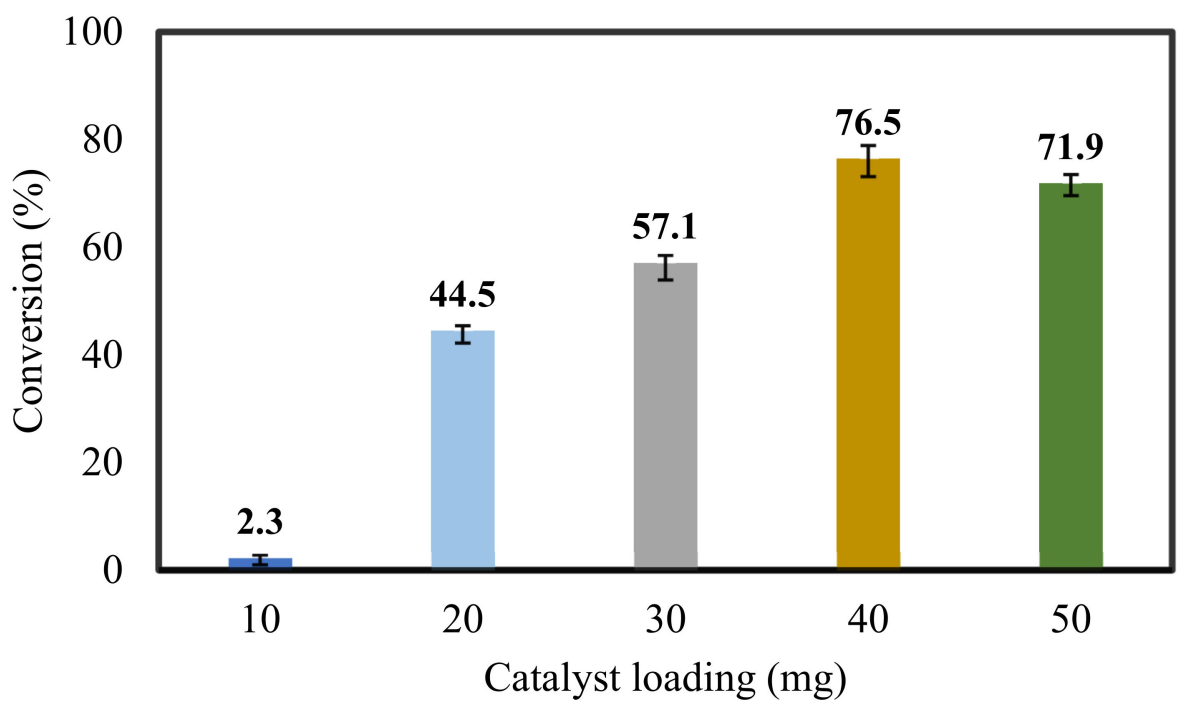

Figure 11. Effect of @PdCassCat loading. Conditions: furfural (10 mmol), base $\left(\mathrm{Et}_{3} \mathrm{~N}\right)(10 \mathrm{mmol})$, formic acid $(20 \mathrm{mmol})$, temperature $160^{\circ} \mathrm{C}$, time $(24 \mathrm{~h})$.

To examine the effect of reaction time on the furfural conversion, the reaction was performed at a constant optimum temperature of $160{ }^{\circ} \mathrm{C}$ and catalyst loading of $40 \mathrm{mg}$ for both catalysts in the time range of 6-24 h (Figure 12). The conversion increased with an increase in reaction time with $100 \%$ selectivity toward furfuryl alcohol. The difference between 18 and $24 \mathrm{~h}$ yield for @PdCassCat catalyst was not significant, hence the optimal time was selected as $24 \mathrm{~h}$. The @PtCassCat catalyst yielded total conversion (100\%) (Table 5, entry 13) even at shorter reaction time of six hours. It has been reported in the literature that the use of conventional Pt catalysts for furfural hydrogenation demonstrated selective hydrogenation of furfural over Pt (Pt: $0.5 \mathrm{wt} \%$ ) based catalysts supported on modified multiwalled carbon nanotubes and with the highest conversion and selectivity of furfuryl alcohol with a yield of $87.4 \%$; however, in this study a total conversion was achieved with a lower bio-ore $\mathrm{Pt}$ catalyst loading of $0.24 \mathrm{wt} \%$ [49]. 


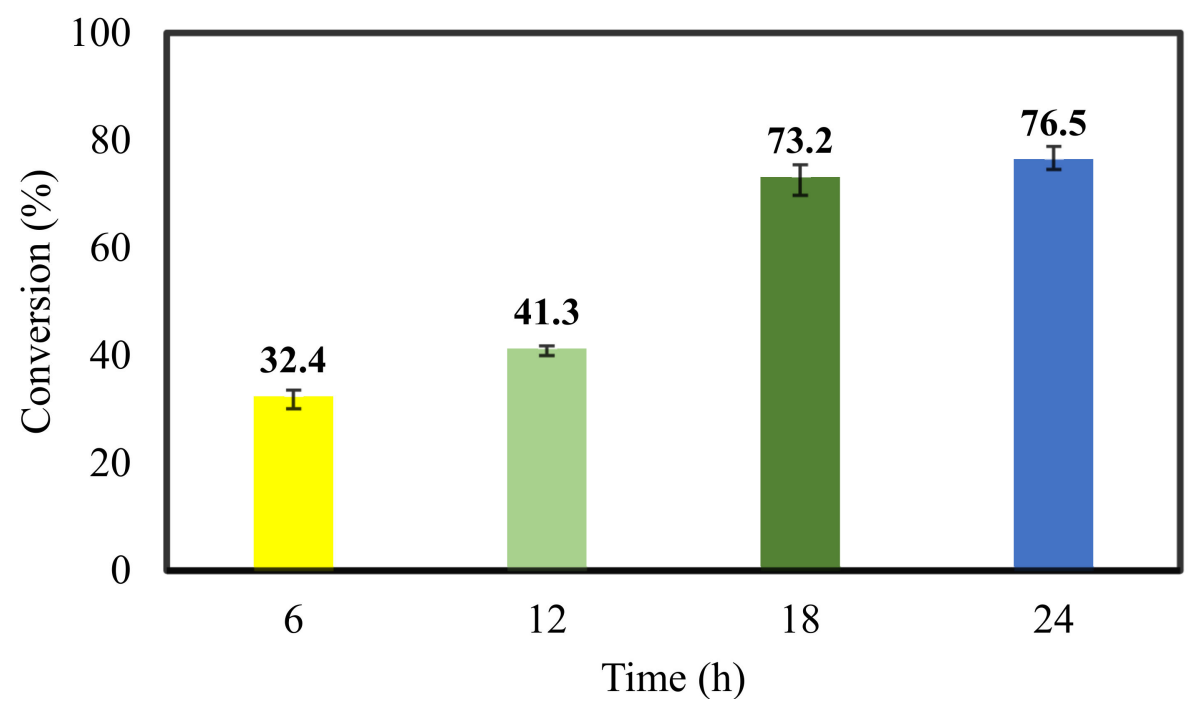

Figure 12. Influence of reaction time on furfural conversion. Conditions: furfural (10 mmol), base $\left(\mathrm{Et}_{3} \mathrm{~N}\right)(10 \mathrm{mmol})$, formic acid $(20 \mathrm{mmol})$, temperature $160^{\circ} \mathrm{C}$, @PdCassCat catalyst amount $(40 \mathrm{mg})$.

The control biochar sample however gave no conversion at optimum condition (Figure S2).

\subsubsection{Catalyst Reusability}

Catalyst recyclability in heterogeneous catalysis is very important from the cost point of view. In this study, the recycled catalysts exhibited good stability and selectivity for furfural hydrogenation under the optimum conditions and was reused up to four times for $@$ PdCassCat (Figure 13) and five times for @PtCassCat (Figure 14). The main reason for the drop in yield was solely due to loss in catalyst mass, which occurred during recovery (washing/filtration) from $40 \mathrm{mg}$ used initially to $6.43 \mathrm{mg}$ in the fourth run. Similar drop was observed with @PtCassCat catalyst.

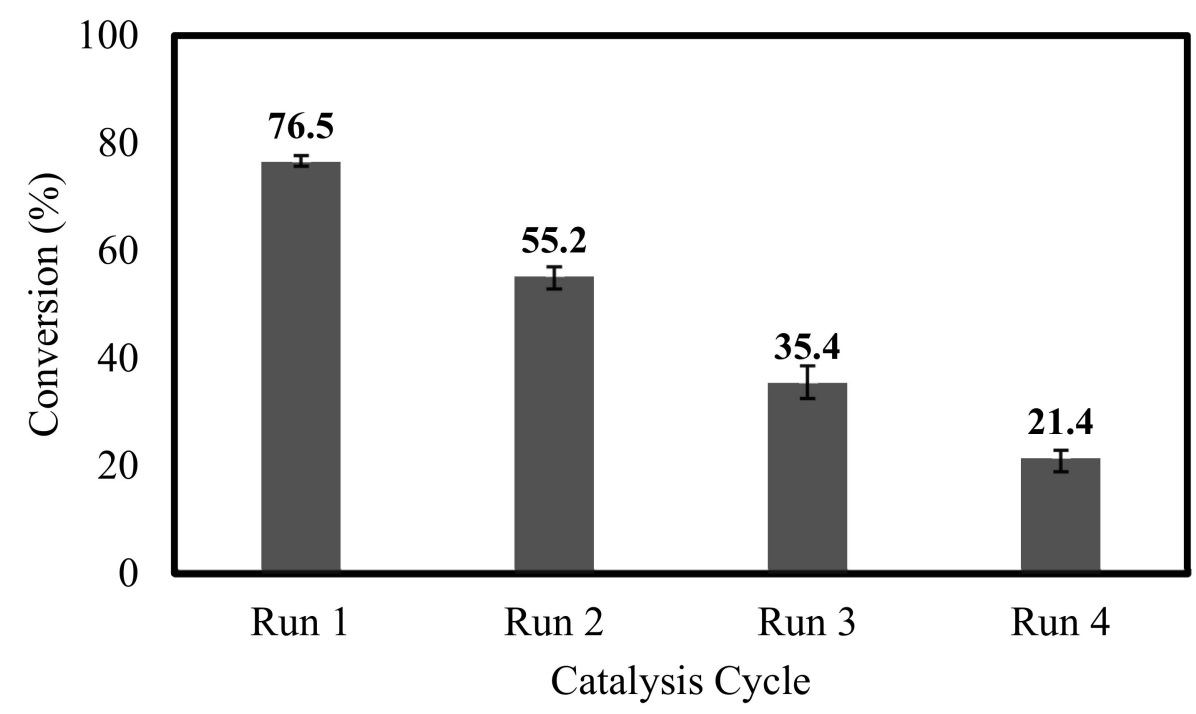

Figure 13. Catalyst recycling study of @PdCassCat catalyst. Reaction conditions: furfural (10 mmol), base $\left(\mathrm{Et}_{3} \mathrm{~N}\right)(10 \mathrm{mmol})$, formic acid $(20 \mathrm{mmol})$, temperature $\left(160^{\circ} \mathrm{C}\right)$, time $(24 \mathrm{~h})$. 


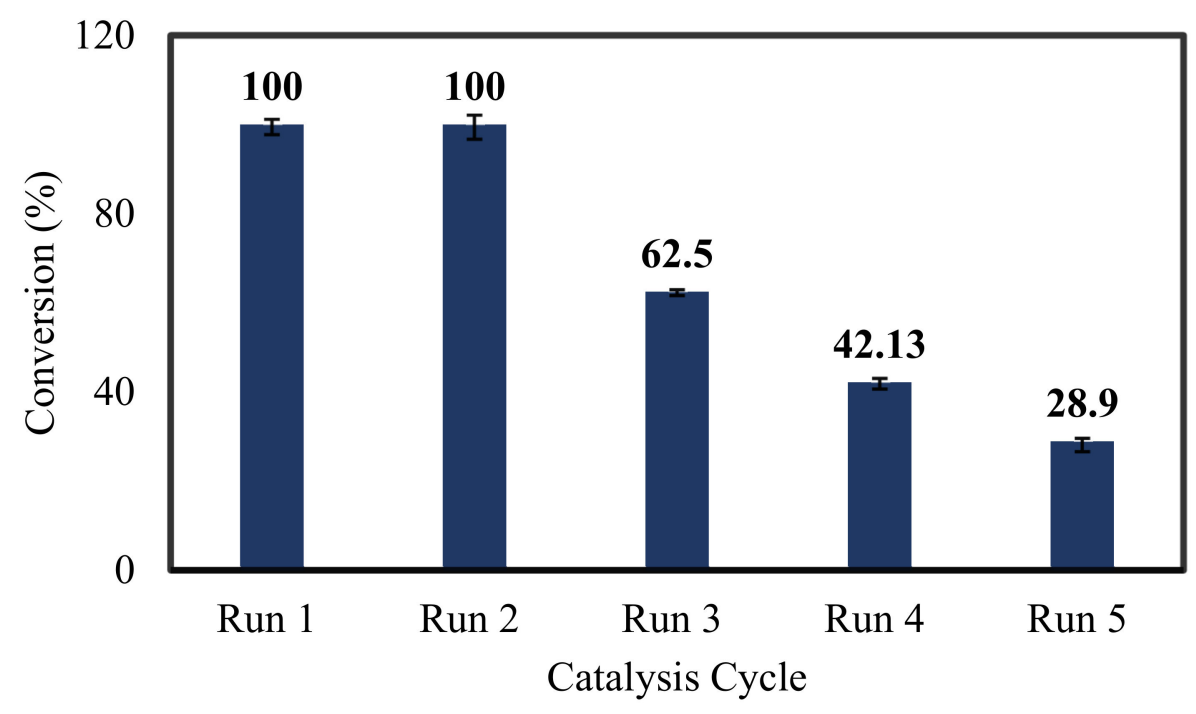

Figure 14. Catalyst recycling study of @PtCassCat catalyst. Reaction conditions: Furfural (10 mmol), base $\left(\mathrm{Et}_{3} \mathrm{~N}\right)(10 \mathrm{mmol})$, formic acid $(20 \mathrm{mmol})$, temperature $\left(160^{\circ} \mathrm{C}\right)$, time $(24 \mathrm{~h})$.

\section{Conclusions}

This study demonstrates an interesting case for plant-synthesized Pd and Pt bioore with proven catalytic functions of the nanoparticle-rich matrix, which promote the conversion of renewable biomass precursor (furfural) into valuable chemicals like furfuryl alcohol. These results on furfural hydrogenation are promising to realize a total conversion with @PtCassCat $(0.24 \mathrm{wt} \%)$ and $76.5 \%$ with @PdCassCat (0.0156 wt \%). The phytomining process, which involves not only restoring our lands but also regaining scarce and lost minerals such as PGMs, demonstrates sustainability and eco-friendly protocol, culminating in a positive step toward saving our climate from rising pollution and worsening energy crises caused by excessive exploitation and depletion of fossil fuels. To the best of our knowledge, this is the first report on selective hydrogenation of furfural to furfuryl alcohol using bio-ore catalyst derived from phytomining technology.

There is still further work to undertake, like practicing the phytomining on commercial scale with already established/proven plant and exploring other similar substrates apart from furfural in catalysis technology.

Supplementary Materials: The following are available online at https:/ /www.mdpi.com/article/10 $.3390 / \mathrm{min} 11080895 / \mathrm{s} 1$, Figure S1: 1H NMR spectrum with (@PtCassCat) showing total conversion of furfural (FF) to furfuryl alcohol (FA), Figure S2: 1H NMR of control biomass sample without product formation.

Author Contributions: Conceptualization, B.J.A., B.C.E.M. and A.A.A.; Data curation, B.J.A. and L.C.M.; Formal analysis, B.J.A.; Funding acquisition, B.C.E.M. and A.A.A.; Investigation, B.J.A., L.C.M., B.C.E.M. and A.A.A.; Methodology, B.J.A., L.C.M., B.C.E.M. and A.A.A.; Project administration, B.C.E.M. and A.A.A.; Resources, B.C.E.M. and A.A.A.; Software, B.J.A.; Supervision, B.C.E.M. and A.A.A.; Validation, B.J.A., L.C.M., B.C.E.M. and A.A.A.; Visualization, B.J.A., L.C.M., B.C.E.M. and A.A.A.; Writing, original draft, B.J.A.; Writing-review \& editing, L.C.M., B.C.E.M. and A.A.A. All authors have read and agreed to the published version of the manuscript.

Funding: The authors acknowledge the National Research Foundation of South Africa in conjunction with the World Academy of Science (NRF-TWAS), grant numbers: 110847 and 117989, as well as the UJ Global Excellence and Stature 4.0 (GES 4.0) programme for the financial support. The authors would also like to acknowledge the University of Johannesburg's Research Centre for Synthesis and Catalysis for the financial support and Spectrum for making their facilities available.

Data Availability Statement: The data that supports the findings of this study are available in the Supplementary Materials of this article. 
Conflicts of Interest: The authors declare no conflict of interest. The funders had no role in the design of the study; in the collection, analyses, or interpretation of data; in the writing of the manuscript, or in the decision to publish the results.

\section{References}

1. Bini, C.; Maleci, L.; Wahsha, M. Mine Waste: Assessment of Environmental Contamination and Restoration; Elsevier Inc.: Amsterdam, The Netherlands, 2017; ISBN 9780128095881.

2. Mhlongo, S.E.; Dacosta, F.A.; Mphephu, N.F. In search of appropriate rehabilitation strategies for abandoned Nyala magnesite mine, Limpopo province of south Africa. Int. J. Eng. Appl. Sci. 2013, 2, 18-30.

3. Pollmann, O.; Meyer, S.; Blumenstein, O.; Van Rensburg, L. Mine tailings: Waste or valuable resource? Waste Biomass Valoriz. 2010, 1, 451-459. [CrossRef]

4. Stacey, J.; Naude, A.; Hermanus, M. The socio-economic aspects of mine closure and sustainable development Scope of work and approach. J. S. Afr. Inst. Min. Metall. 2010, 110, 378-394.

5. Brooks, R.R. Plants that Hyperaccumulate Heavy Metals, Their Role in Phytoremediation, Microbiology, Archaeology, Mineral Exploration and Phytomining; CAB International: New York, NY, USA, 1998; p. 289.

6. Anderson, C.W.N.; Brooks, R.R.; Stewart, R.B.; Simcock, R. Harvesting a crop of gold in plants. Nature 1998, 395, 553-554. [CrossRef]

7. Anderson, C.W.N. Hyperaccumulation by plants. RSC Green Chem. 2013, 22, 114-139.

8. Anderson, C.W.N.; Brooks, R.R.; Chiarucci, A.; Lacoste, C.J.; Leblanc, M.; Robinson, B.H.; Simcock, R.; Stewart, R.B. Phytomining for nickel, thallium and gold. J. Geochem. Explor. 1999, 67, 407-415. [CrossRef]

9. McGrath, S.P.; Sidoli, C.M.D.; Baker, A.J.M.; Reeves, R.D. The Potential for the Use of Metal-Accumulating Plants for the In Situ Decontamination of Metal-Polluted Soils; Springer: Dordrecht, The Netherlands, 1993; pp. 673-676.

10. Piccinin, R.C.R.; Ebbs, S.D.; Reichman, S.M.; Kolev, S.D.; Woodrow, I.E.; Baker, A.J.M. A screen of some native Australian flora and exotic agricultural species for their potential application in cyanide-induced phytoextraction of gold. Miner. Eng. 2007, 20, 1327-1330. [CrossRef]

11. Harumain, Z.A.S.; Parker, H.L.; Muñoz García, A.; Austin, M.J.; McElroy, C.R.; Hunt, A.J.; Clark, J.H.; Meech, J.A.; Anderson, C.W.N.; Ciacci, L.; et al. Toward Financially Viable Phytoextraction and Production of Plant-Based Palladium Catalysts. Environ. Sci. Technol. 2017, 51, 2992-3000. [CrossRef]

12. Lamb, A.E.; Anderson, C.W.N.; Haverkamp, R.G. The Induced Accumulation of Gold in the Plants. Brassica juncea, Berkheya coddii and Chicory. Chem. New Zealand 2001, 9, 34-36.

13. Alcantara, H.J.P.; Doronila, A.I.; Kolev, S.D. Phytoextraction potential of Manihot esculenta Crantz. (cassava) grown in mercuryand gold-containing biosolids and mine tailings. Miner. Eng. 2017, 114, 57-63. [CrossRef]

14. Adjorlolo-Gasokpoh, A.; Golow, A.A.; Kambo-Dorsa, J. Mercury in the Surface Soil and Cassava, Manihot esculenta (Flesh, Leaves and Peel) Near Goldmines at Bogoso and Prestea, Ghana. Bull. Environ. Contam. Toxicol. 2012, 89, 1106-1110. [CrossRef]

15. Hunt, A.J.; Anderson, C.W.N.; Bruce, N.; García, A.M.; Graedel, T.E.; Hodson, M.; Meech, J.A.; Nassar, N.T.; Parker, H.L.; Rylott, E.L.; et al. Phytoextraction as a tool for green chemistry. Green Process. Synth. 2014, 3, 3-22. [CrossRef]

16. Parker, H.L.; Rylott, E.L.; Hunt, A.J.; Dodson, J.R.; Taylor, A.F.; Bruce, N.C.; Clark, J.H. Supported palladium nanoparticles synthesized by living plants as a catalyst for Suzuki-Miyaura reactions. PLoS ONE 2014, 9, e29590. [CrossRef] [PubMed]

17. Makhubela, B.C.E.; Darkwa, J. The Role of Noble Metal Catalysts in Conversion of Biomass and Bio-derived Intermediates to Fuels and Chemicals. Johns. Matthey Technol. Rev. 2018, 62, 4-31. [CrossRef]

18. Tukacs, J.M.; Bohus, M.; Dibó, G.; Mika, L.T. Ruthenium-catalyzed solvent-free conversion of furfural to furfuryl alcohol. RSC Adv. 2017, 7, 3331-3335. [CrossRef]

19. Gong, W.; Chen, C.; Fan, R.; Zhang, H.; Wang, G.; Zhao, H. Transfer-hydrogenation of furfural and levulinic acid over supported copper catalyst. Fuel 2018, 231, 165-171. [CrossRef]

20. Parikh, J.; Srivastava, S.; Jadeja, G.C. Selective Hydrogenation of Furfural to Tetrahydrofurfuryl Alcohol Using Supported Nickel-Cobalt Catalysts. Ind. Eng. Chem. Res. 2019, 58, 16138-16152. [CrossRef]

21. Sitthisa, S.; An, W.; Resasco, D.E. Selective conversion of furfural to methylfuran over silica-supported NiFe bimetallic catalysts. J. Catal. 2011, 284, 90-101. [CrossRef]

22. Wang, Y.; Zhao, D.; Liang, R.; Triantafyllidis, K.S.; Yang, W.; Len, C. Transfer hydrogenation of furfural to furfuryl alcohol over modified Zr-based catalysts using primary alcohols as H-donors. Mol. Catal. 2021, 499, 111199. [CrossRef]

23. Rao, R.S.; Baker, R.T.K.; Vannice, M.A. Furfural hydrogenation over carbon-supported copper. Catal. Lett. 1999, 60, 51-57. [CrossRef]

24. Gong, W.; Chen, C.; Zhang, Y.; Zhou, H.; Wang, H.; Zhang, H.; Zhang, Y.; Wang, G.; Zhao, H. Efficient Synthesis of Furfuryl Alcohol from H2-Hydrogenation/Transfer Hydrogenation of Furfural Using Sulfonate Group Modified Cu Catalyst. ACS Sustain. Chem. Eng. 2017, 5, 2172-2180. [CrossRef]

25. Zhang, H.; Canlas, C.; Jeremy Kropf, A.; Elam, J.W.; Dumesic, J.A.; Marshall, C.L. Enhancing the stability of copper chromite catalysts for the selective hydrogenation of furfural with ALD overcoating (II)-Comparison between $\mathrm{TiO}_{2}$ and $\mathrm{Al}_{2} \mathrm{O}_{3}$ overcoatings. J. Catal. 2015, 326, 172-181. [CrossRef] 
26. Nagaraja, B.M.; Siva Kumar, V.; Shasikala, V.; Padmasri, A.H.; Sreedhar, B.; David Raju, B.; Rama Rao, K.S. A highly efficient $\mathrm{Cu} / \mathrm{MgO}$ catalyst for vapour phase hydrogenation of furfural to furfuryl alcohol. Catal. Commun. 2003, 4, 287-293. [CrossRef]

27. Taylor, M.J.; Durndell, L.J.; Isaacs, M.A.; Parlett, C.M.A.; Wilson, K.; Lee, A.F.; Kyriakou, G. Highly selective hydrogenation of furfural over supported Pt nanoparticles under mild conditions. Appl. Catal. B Environ. 2016, 180, 580-585. [CrossRef]

28. Vaidya, P.D.; Mahajani, V.V. Kinetics of liquid-phase hydrogenation of furfuraldehyde to furfuryl alcohol over a Pt/C catalyst. Ind. Eng. Chem. Res. 2003, 42, 3881-3885. [CrossRef]

29. Fulajtárova, K.; Soták, T.; Hronec, M.; Vávra, I.; Dobročka, E.; Omastová, M. Aqueous phase hydrogenation of furfural to furfuryl alcohol over Pd-Cu catalysts. Appl. Catal. A Gen. 2015, 502, 78-85. [CrossRef]

30. Mekonnen, K.N.; Ambushe, A.A.; Chandravanshi, B.S.; Redi-Abshiro, M. Assessment of potentially toxic elements in Swiss chard and sediments of Akaki River, Ethiopia. Toxicol. Environ. Chem. 2014, 96, 1501-1515. [CrossRef]

31. Moyo, P.S.; Matsinha, L.C.; Makhubela, B.C.E. Pd(II) and Pt(II) catalysed selective synthesis of furfuryl alcohol: Solvent effects and insights into the mechanism. J. Organomet. Chem. 2020, 922, 121362. [CrossRef]

32. Wu, W.; Zhao, W.; Fang, C.; Wang, Z.; Yang, T.; Li, H.; Yang, S. Quantitative hydrogenation of furfural to furfuryl alcohol with recyclable KF and hydrosilane at room temperature in minutes. Catal. Commun. 2018, 105, 6-10. [CrossRef]

33. Gawrońska, H.; Przybysz, A.; Szalacha, E.; Pawlak, K.; Brama, K.; Miszczak, A.; Stankiewicz-Kosyl, M.; Gawroński, S.W. Platinum uptake, distribution and toxicity in Arabidopsis thaliana L. plants. Ecotoxicol. Environ. Saf. 2018, 147, 982-989. [CrossRef]

34. Lesniewska, B.A.; Messerschmidt, J.; Jakubowski, N.; Hulanicki, A. Bioaccumulation of platinum group elements and characterization of their species in Lolium multiflorum by size-exclusion chromatography coupled with ICP-MS. Sci. Total Environ. 2004, 322, 95-108. [CrossRef] [PubMed]

35. Schäfer, J.; Hannker, D.; Eckhardt, J.D.; Stüben, D. Uptake of traffic-related heavy metals and platinum group elements (PGE) by plants. Sci. Total Environ. 1998, 215, 59-67. [CrossRef]

36. Arsiya, F.; Sayadi, M.H.; Sobhani, S. Green synthesis of palladium nanoparticles using Chlorella vulgaris. Mater. Lett. 2017, 186, 113-115. [CrossRef]

37. Ha, C.; Zhu, N.; Shang, R.; Shi, C.; Cui, J.; Sohoo, I.; Wu, P.; Cao, Y. Biorecovery of palladium as nanoparticles by Enterococcus faecalis and its catalysis for chromate reduction. Chem. Eng. J. 2016, 288, 246-254. [CrossRef]

38. Targhan, H.; Hassanpour, A.; Sohrabnezhad, S.; Bahrami, K. Palladium Nanoparticles Immobilized with Polymer Containing Nitrogen-Based Ligand: A Highly Efficient Catalyst for Suzuki-Miyaura and Mizoroki-Heck Coupling Reactions. Catal. Lett. 2020, 150, 660-673. [CrossRef]

39. Shaik, M.R.; Ali, Z.J.Q.; Khan, M.; Kuniyil, M.; Assal, M.E.; Alkhathlan, H.Z.; Al-Warthan, A.; Siddiqui, M.R.H.; Khan, M.; Adil, S.F. Green Synthesis and Characterization of Palladium Nanoparticles Using Origanum vulgare L. Extract and Their Catalytic Activity. Molecules 2017, 22, 165. [CrossRef]

40. Bendre, A.D.; Patil, V.P.; Terdale, S.S.; Kodam, K.M.; Waghmode, S.B. A simple, efficient and green approach for the synthesis of palladium nanoparticles using Oxytocin: Application for ligand free Suzuki reaction and total synthesis of aspongpyrazine A. J. Organomet. Chem. 2020, 909, 121093. [CrossRef]

41. Siddiqi, K.S.; Husen, A. Green Synthesis, Characterization and Uses of Palladium/Platinum Nanoparticles. Nanoscale Res. Lett. 2016, 11, 1-13. [CrossRef]

42. Al-Marri, A.H.; Khan, M.; Shaik, M.R.; Mohri, N.; Adil, S.F.; Kuniyil, M.; Alkhathlan, H.Z.; Al-Warthan, A.; Tremel, W.; Tahir, M.N.; et al. Green synthesis of Pd@graphene nanocomposite: Catalyst for the selective oxidation of alcohols. Arab. J. Chem. 2016, 9, 835-845. [CrossRef]

43. Jameel, M.S.; Aziz, A.A.; Dheyab, M.A.; Mehrdel, B.; Khaniabadi, P.M. Rapid sonochemically-assisted green synthesis of highly stable and biocompatible platinum nanoparticles. Surf. Interfaces 2020, 20, 100635. [CrossRef]

44. Asztemborska, M.; Steborowski, R.; Kowalska, J.; Bystrzejewska-Piotrowska, G. Accumulation of platinum nanoparticles by Sinapis alba and Lepidium sativum plants. Water Air Soil Pollut. 2015, 226, 126. [CrossRef] [PubMed]

45. Bali, R.; Siegele, R.; Harris, A.T. Biogenic Pt uptake and nanoparticle formation in Medicago sativa and Brassica juncea. J. Nanopart. Res. 2010, 12, 3087-3095. [CrossRef]

46. Sing, K.S.W.; Everett, D.H.; Haul, R.A.W.; Moscou, L.; Pierotti, R.A.; Rouquerol, J.; Siemieniewska, T. Reporting Physisorption Data for Gas/Solid Systems with Special Reference to the Determination of Surface Area and Porosity. Pure Appl. Chem. 1985, 57, 603-619. [CrossRef]

47. Thommes, M.; Kaneko, K.; Neimark, A.V.; Olivier, J.P.; Rodriguez-Reinoso, F.; Rouquerol, J.; Sing, K.S.W. Physisorption of gases, with special reference to the evaluation of surface area and pore size distribution (IUPAC Technical Report). Pure Appl. Chem. 2015, 87, 1051-1069. [CrossRef]

48. Ramana, D.V.; Pillai, C.N. Hydrogen transfer reactions. I. Reduction of carbonyl compounds by alcohols catalyzed by alumina. Can. J. Chem. 1969, 47, 3705-3707. [CrossRef]

49. Xu, Y.; Qiu, S.; Long, J.; Wang, C.; Chang, J.; Tan, J.; Liu, Q.; Ma, L.; Wang, T.; Zhang, Q. In situ hydrogenation of furfural with additives over. RSC Adv. 2015, 5, 91190-91195. [CrossRef] 
50. Nguyen, L.T.M.; Park, H.; Banu, M.; Kim, J.Y.; Youn, D.H.; Magesh, G.; Kim, W.Y.; Lee, J.S. Catalytic $\mathrm{CO}_{2}$ hydrogenation to formic acid over carbon nanotube-graphene supported PdNi alloy catalysts. RSC Adv. 2015, 5, 105560-105566. [CrossRef]

51. Silva, W.R.; Matsubara, E.Y.; Rosolen, J.M.; Donate, P.M.; Gunnella, R. Pd catalysts supported on different hydrophilic or hydrophobic carbonaceous substrate for furfural and 5-(hydroxymethyl)-furfural hydrogenation in water. Mol. Catal. 2021, 504, 111496. [CrossRef] 